\title{
PBPK modeling of the cis- and trans- permethrin isomers and their major urinary metabolites in rats
}

Marie-Emilie Willemin ${ }^{\text {a, b, } 1}$, Sophie Desmots ${ }^{\text {c }}$, Rozenn Le Grand ${ }^{\mathrm{d}}$, François Lestremau ${ }^{\mathrm{e}}$, Florence A. Zeman ${ }^{\text {a }}$, Eric Leclerc ${ }^{\mathrm{b}}$, Christian Moesch ${ }^{\mathrm{d}}$, Céline Brochot ${ }^{\mathrm{a}, *}$

a Institut National de 1'Environnement Industriel et des Risques (INERIS), Unité Modèles pour l'Ecotoxicologie et la Toxicologie (METO), Parc ALATA BP2, 60550 Verneuil en Halatte, France

b Sorbonne University, Université de Technologie de Compiègne, CNRS, UMR 7338 Biomechanics and Bioengineering, Centre de recherche Royallieu - CS 60319 - 60203 Compiègne Cedex, France

c Institut National de l'Environnement Industriel et des Risques (INERIS), Unité Toxicologie Expérimentale (TOXI), Parc ALATA BP2, 60550 Verneuil en Halatte, France

${ }^{d}$ Centre Hospitalo-Universitaire de Limoges, Service de Pharmacologie et de Toxicologie Pharmacovigilance, 2, avenue Martin Luther King, 87042 Limoges, France

e Institut National de l'Environnement Industriel et des Risques (INERIS), Unité Innovation pour la Mesure (NOVA), Parc ALATA BP2, 60550 Verneuil en Halatte, France

${ }^{1}$ Present address :

US Food and Drug Administration (FDA), National Center for Toxicological Research (NCTR), Division of Biochemical Toxicology, 3900 NCTR Road, Jefferson, AR 72079, United States

* Corresponding author: Céline Brochot

Institut National de 1'Environnement Industriel et des Risques (INERIS), Unité Modèles pour l'Ecotoxicologie et la Toxicologie (METO), Parc ALATA BP2, 60550 Verneuil en Halatte, France

Tel: +33344556850

Fax: +33 344556767

Email: celine.brochot@ineris.fr 


\begin{abstract}
Permethrin, a pyrethroid insecticide, is suspected to induce neuronal and hormonal disturbances in humans. The widespread exposure of the populations has been confirmed by the detection of the urinary metabolites of permethrin in biomonitoring studies. Permethrin is a chiral molecule presenting two forms, the cis and the trans isomers. Because in vitro studies indicated a metabolic interaction between the trans and cis isomers of permethrin, we adapted and calibrated two PBPK models for trans- and cis-permethrin in rats. The models also describe the toxicokinetics of three urinary metabolites, cis- and trans-3-(2,2 dichlorovinyl)-2,2-dimethyl-(1-cyclopropane) carboxylic acid (cisand trans-DCCA), 3-phenoxybenzoic acid (3-PBA) and 4'OH-phenoxybenzoic acid (4'-OH-PBA). In vivo experiments performed in Sprague-Dawley rats were used to calibrate the PBPK models in a Bayesian framework. The model captured well the toxicokinetics of permethrin isomers and their metabolites including the rapid absorption, the accumulation in fat and the extensive metabolism of the parent compounds, and the rapid elimination of metabolites in urine. Average hepatic clearances in rats were estimated to be 2.4 and $5.7 \mathrm{~L} / \mathrm{h} / \mathrm{kg}$ for cis- and trans-permethrin, respectively. High concentrations of the metabolite 4'-OH-PBA were measured in urine compared to cis- and transDCCA and 3-PBA. The confidence in the extended PBPK model was then confirmed by good predictions of published experimental data obtained using the isomers mixture. The extended PBPK model could be extrapolated to humans to predict the internal dose of exposure to permethrin from biomonitoring data in urine.
\end{abstract}

Keywords: PBPK model, cis/trans-permethrin, 3-phenoxybenzoic acid, cis- and trans-3-(2,2 dichlorovinyl)-2,2-dimethyl-(1-cyclopropane) carboxylic acid, Bayesian calibration, metabolites 


\section{Introduction}

Pyrethroid insecticides are used in household applications, agriculture or medicine (US EPA, 2011). Their consumption increased recently, probably in response to restrictions on the use of other insecticides such as organophosphates and organochlorines. Because pyrethroids are rapidly metabolized, human exposure is usually assessed by measuring the urinary concentrations of their metabolites, including 3-phenoxybenzoic acid (3-PBA) and cis- and trans-3-(2,2 dichlorovinyl)-2,2dimethyl-(1-cyclopropane) carboxylic acid (cis and trans-DCCA). These metabolites can either be specific to a pyrethroid (e.g., 3-(2,2-dibromovinyl)-2,2-dimethylcyclopropane-1-carboxylic acid for deltamethrin) or common to several ones (e.g., 3-PBA). The widespread exposure of humans was confirmed in biomonitoring studies, carried out in different countries such as France, Germany, USA and Japan, where the biomarkers of exposure were detected in almost all the individuals tested (Egerer et al., 2004; Heudorf et al., 2006; Barr et al., 2010; Ueyama et al., 2010; Morgan, 2012; InVS, 2013). In particular, these different studies demonstrated the large exposure of the French population to pyrethroids since the common metabolite 3-PBA was recovered at high amounts in urine with a 2 and 3 -factor compared to the other countries.

Among pyrethroids, permethrin (3-phenoxybenzyl (1RS,3RS;1RS,3SR)-cis,trans-3-(2,2dichlorovinyl)-2,2-dimethylcyclo-propanecarboxylate) is one of the most commonly used especially in household applications (US EPA, 2005; Stout et al., 2009). Like other pyrethroids, permethrin acts on the nervous system of insects and mammals by interfering with neuronal voltage-gated sodium channels to disrupt the function of neurons (Soderlund et al., 2002; Soderlund, 2012). In mammals, permethrin is suspected to induce disturbances on the neuronal and hormonal systems. Syndrome T (aggressive sparring, fine tremors) (Verschoyle and Aldridge, 1980; Wolansky and Harrill, 2008) and reproductive modifications, especially on testosterone levels (Zhang et al., 2007; Zhang et al., 2008; Jin et al., 2012) were observed in rats after acute and chronic exposures respectively. In humans, the reported adverse effects are skin irritation, paraesthesia or headaches depending on the routes of exposure (Lequesne et al., 1981; Flannigan et al., 1985; He et al., 1989; Gotoh et al., 1998; Bradberry et al., 2005). Epidemiological studies have also shown associations between modifications of the 
semen quality and the presence of pyrethroids metabolites in urines (Meeker et al., 2008; Young et al., 2013; Imai et al., 2014).

Permethrin has four stereoisomers due to the two chiral carbons on the cyclopropane rings. The cisand trans-isomers are comprised of enantiomers 1R,S-cis-permethrin and 1R,S-trans-permethrin. Metabolic interactions between the cis and trans isomers of permethrin have been previously observed in vitro using hepatic microsomes (Scollon et al., 2009). The intrinsic hepatic clearances of the binary mixture were found to be reduced compared to that of the individual isomers; by $39 \%$ for trans-permethrin in rats and a factor 2 for both isomers in humans. Such metabolic interactions could contribute to the increased time of residence of the permethrin isomers (active form) in the body potentially predisposing the organism to its associated risks. Since the ratio of the permethrin isomers in the environment is not precisely known and is not constant, it is necessary to characterize first the toxicokinetics of each isomer separately and then link them using a specific model that accounts for their metabolic interactions.

In this paper, we propose to develop and calibrate a PBPK model for cis- and trans-permethrin in a Bayesian framework using data obtained from new in vivo experiments in rats exposed to the individual isomers. The PBPK model developed here is an extension of the PBPK models previously published (Tornero-Velez et al., 2012; Wei et al., 2013). The extended PBPK model includes the kinetic of the isomer of permethrin in additional organs and integrates the toxicokinetics of the three urinary metabolites that are commonly used as biomarkers of permethrin exposure (3-PBA, cis- and trans-DCCA) and the metabolite 4'OH-phenoxybenzoic acid (4'-OH-PBA) a major metabolite of permethrin (Takaku et al., 2011). 


\section{Materials and Methods}

\section{Chemicals}

Cis-permethrin

(3-phenoxybenzyl(1RS)-cis-3-(2,2-dichlorovinyl)-2,2-dimethylcyclopropane carboxylate, $99.4 \%$ purity) and trans-permethrin (3-phenoxybenzyl (1RS)-trans-3-(2,2dichlorovinyl)-2,2-dimethylcyclopropanecarboxylate, 99\% purity) were obtained from ChemService (West Chester, USA) and Dr. Ehrenstorfer (Augsburg, Germany), respectively. The internal standards cis- $\left[{ }^{13} \mathrm{C}_{6}\right]$ permethrin (98\% purity) and trans- $\left[{ }^{13} \mathrm{C}_{2}\right] \mathrm{DCCA}$ (98\% purity) were purchased from LGC standard (Cambridge Isotope Laboratories, USA). Corn oil was acquired from Sygma-Aldrich (St Quentin Fallavier, France).

\section{Animals}

Adult male Sprague-Dawley rats were purchased from Janvier (Genet de lisle, France). They weighed $468 \mathrm{~g} \pm 21 \mathrm{~g}$ (mean body weight $(\mathrm{BW}) \pm$ standard deviation $(\mathrm{SD}))$ and were $90-100$ days old at the time of the experiments. The experimental protocol was approved by an internal ethics committee. Each rat was housed in a cage with a $12 \mathrm{~h}$ light/ $12 \mathrm{~h}$ dark cycle at ambient temperature $\left(22^{\circ} \mathrm{C} \pm 2^{\circ} \mathrm{C}\right)$ and relative humidity $(55 \pm 15 \%)$. Food (Altromin for rat and mouse, Genestril, Royaucourt, France) and tap water were provided ad libitum. The rats were allowed a minimum acclimation period of 4 days before experiments. Rats were not fasted before the administration of permethrin, as it was previously done for toxicokinetic studies on deltamethrin (Godin et al., 2010) and permethrin (Tornero-Velez et al., 2012)

\section{Experiments}

A dose of $25 \mathrm{mg} / \mathrm{kg}$ of either cis- or trans-permethrin dissolved in corn oil $(2 \mathrm{~mL} / \mathrm{kg})$ was administered to rats by gavage. The same solvent (corn oil) as the one used in previous toxicokinetic studies on pyrethroids was kept to insure reliable comparisons, since the nature of the solvent can have an impact on the absorption process in case of highly lipophilic chemicals like permethrin (Soderlund et al., 2002). Based on our preliminary study (Lestremau et al., 2014), at the dose of 20 $\mathrm{mg} / \mathrm{kg}$ of permethrin, both parents and metabolites were quantified in most of the matrices with our 
analytical procedure, and no side effects were observed in rats. The dose was increased in our current study by a 0.25 -fold to insure the quantification of all the compounds in all the matrices. Access to food was provided $3 \mathrm{~h}$ after dosing. Groups of 4 rats were sacrificed with $\mathrm{CO}_{2}$ at $0.5,1,1.5,2,4,6,10$, 24, $48 \mathrm{~h}$ and 6 days after administration. For the time points below $24 \mathrm{~h}$, the rats were housed individually in a metabolic cage until euthanasia with $\mathrm{CO}_{2}$. Because the time residence of the rats in the metabolic cage was limited to $24 \mathrm{~h}$ consecutively, several groups of rats were considered for the time points $48 \mathrm{~h}$ and 6 days. Urine and feces were then collected on $24 \mathrm{~h}$ intervals and were then cumulated.

Immediately after the euthanasia of the rat, blood samples were drawn from the inferior vena cava and collected in heparinized tubes. Formic acid $1 \%$ was added V/V to blood to inhibit the metabolism of permethrin due to carboxylesterases (CE) enzymes and to preserve the stability of the compounds. The median liver lobe, the perirenal fat, the muscle of the right thigh, the right kidney, the right testis and the brain were isolated and weighed. Urine and feces were collected every day in a metabolic cage until the $6^{\text {th }}$ day. All matrices were frozen at $-80^{\circ} \mathrm{C}$ until analysis. No precautions were taken during the collection of the urine since no specific procedures were described for similar studies on pyrethroids metabolites in the literature (Kühn et al., 1996; Leng and Gries, 2005).

\section{Chemical analyses}

The extraction and detection of analytes in organs and feces were performed by GC-MS/MS based on the analytical method developed by Lestremau et al. (2014). Parent compounds cis- and transpermethrin were dosed in each matrix and the metabolites cis- and trans-DCCA in blood, liver and feces. All the organs were thawed and ground with a mortar and a pestle and then with microbeads using a Precellys homogenizer (Bertin, Montigny le Bretonneux, France). The internal standards cis$\left[{ }^{13} \mathrm{C}_{6}\right]$ permethrin and trans- $\left[{ }^{13} \mathrm{C}_{2}\right] \mathrm{DCC} A$ were added to the matrix before the microbeads step. Then, $1 \mathrm{~g}$ (or $\mathrm{mL}$ ) of the matrix (except urine), containing the target analytes and their internal standards, was treated by a methanolic/hydrochloric acid solution. This step ensures the derivatization of the metabolites and the cleavage of the conjugated metabolites. The methanolic/hydrochloric acid solution has no impact on the recovery of permethrin, as pointed out by Lestremau et al. (2014). The 
different compounds were then extracted with toluene. The extraction of permethrin in fat was performed with an acetonitrile/dichloromethane solution containing a purification step with a blend of Strata X-AW and $\mathrm{Na}_{2} \mathrm{SO}_{4}$. A column ZB-5MS $(30 \mathrm{~m} \times 0.25 \mathrm{~mm}$ I.D., $1 \mu \mathrm{m})$ and a Varian gas chromatograph 3800 coupled with a Varian ion trap mass spectrometer 4000 were used. The limits of quantification were $50 \mu \mathrm{g} / \mathrm{L}$ for cis- and trans-permethrin, and $25 \mu \mathrm{g} / \mathrm{L}$ for cis- and trans-DCCA. When a compound was detected in a sample at a concentration below the limit of quantification (LOQ), the compound concentration was set to $\mathrm{LOQ} / 2$. This approach is quite widely used in toxico/phamacokinetic studies (Beal, 2001; Soucy et al., 2006).

Both parent compounds and metabolites DCCA, 3-PBA and 4'-OH-PBA were quantified in urine by LC-MS/MS (Le Grand et al., 2012). A column Atlantis T3 (150 mm $\times 2.1 \mathrm{~mm}$ I.D., $5 \mu \mathrm{m})$ was required with Shimadzu LC-10 AD pumps coupled with a mass spectrometric AB Sciex API-5000. The LOQ for cis- and trans-DCCA, 3-PBA and 4'-OH-PBA were $8 \mu \mathrm{g} / \mathrm{L}, 12 \mu \mathrm{g} / \mathrm{L}, 10 \mu \mathrm{g} / \mathrm{L}$ and $500 \mu \mathrm{g} / \mathrm{L}$, respectively.

The addition of concentrated hydrochloric acid during the chemical process of the samples insures the cleavage of conjugated bound to metabolites, like 4'-OH-PBA-sulfate (Gaughan et al., 1977; Kühn et al., 1996). The metabolites measured in this study correspond therefore to the free form and newly free form obtained after cleaving the binding conjugation (sulfate, glucuronide). No distinction was made for each metabolite between the conjugated and unconjugated form.

\section{Model structure}

The structure of the PBPK model for cis- and trans-permethrin was based on existing PBPK models developed for Type I and Type II pyrethroids, permethrin as a mixture of the two isomers and deltamethrin (Mirfazaelian et al., 2006; Godin et al., 2010; Tornero-Velez et al., 2012). These models included the following compartments: blood and liver where metabolism occurs, intestinal tract as the route of entry of the compound and as a metabolic site, fat in which permethrin is accumulated, brain as a target tissue for neurotoxicity, and rapidly and poorly perfused tissues. In this current work, the permethrin model proposed by Tornero-Velez et al. (2012) was extended to include additional compartments corresponding to tissues that were analyzed in this study, i.e., testes (a potential target 
tissue), muscle for which permethrin is suspected to have a high partitioning affinity (a high partition coefficient of 5.59 was estimated in the former model) and kidneys as a surrogate for the rapidly perfused tissues. In concurrence with the previous models, the distribution of permethrin (and pyrethroids in general) was described to be instantaneous in several tissues and was modelled as limited by diffusion in brain, fat, muscle, testes and poorly perfused tissues. The description of the distribution of permethrin in these latter as a diffusion-limited process enables to capture the relative slow distribution of permethrin and also to obtain a better agreement between the predictions and the observed concentrations. The other compartments including intestines, kidney, liver, and rapidly perfused tissues were described as flow-limited. The absorption was modelled as described by Godin et al. (2010) for deltamethrin. The oral absorption was composed of two compartments (stomach and gastro-intestinal (GI) tract) with a single constant of absorption $K_{i}$ located in the GI tract. Permethrin was eliminated by metabolism in three compartments (GI tract, blood and liver) and by excretion in feces in the gut lumen (no permethrin was detected in urine). The PBPK model of cis- or transpermethrin contains in total 10 compartments (plus the stomach and GI tract lumens) and is identical in structure for both isomers.

The PBPK models for the permethrin isomers were linked to their respective sub-models describing the kinetics of the metabolites. In rats, permethrin and its oxidized forms are metabolized by CEs in blood, liver, and to a lesser extent in small intestine. Permethrin is hydrolyzed into the metabolites cisand trans-DCCA and the (un)oxidized form of 3-phenoxybenzoic alcohol (Ross et al., 2006; Crow et al., 2007). This (un)oxidized carboxylic acid part, common to several pyrethroids, is then oxidized into the forms 4'OH-phenoxybenzoic acid (4'-OH-PBA) or 3-phenoxybenzoic acid (3-PBAcid), commonly labeled as 3-PBA, in the liver by cytochromes P450 (Gaughan et al., 1977; Nakamura et al., 2007; Takaku et al., 2011; Mikata et al., 2012).

To our best knowledge, the kinetics of permethrin metabolites have not yet been modeled in rats. To extend the extrapolation from rats to humans on a physiological basis for metabolites, a reduced PBPK model was developed for cis- and trans-DCCA and calibrated using measured concentrations in blood, liver, urine and feces. This model includes three compartments; blood, liver, and the rest of 
the body described as a diffusion-limited compartment. The urinary excretion was modeled in blood and the fecal excretion assumed via bile in liver, described by a clearance $\left(K_{\text {uri_DCCA }}\right)$ and a first-order rate $\left(K_{\text {fec } \_D C C A}\right)$, respectively. Two-compartment models for 3-PBA and 4'-OH-PBA were developed to describe their respective urinary elimination kinetics. Metabolites were eliminated from blood to urine with a first order rate constant $\left(K_{\text {uri } X}\right)$, where $X$ denotes the respective metabolites being described. The formation of each metabolite was dependent on the whole production of metabolites in the three metabolic sites and was expressed as a fraction $\left(F r c_{\text {met_X }}\right)$ of the total clearance of $c i s-$ or trans-permethrin:

$$
\frac{d A_{\text {met_ } X}}{d t}=F r a c_{\text {met_ } X} \times\left(R_{\text {liv_PER }}+R_{\text {GI_PER }}+R_{b l l_{-} P E R}\right) \times \frac{M W_{X}}{M W_{\text {PER }}}
$$

where $R_{\text {liv_PER }}, R_{\text {GI_PER }}$ and $R_{\text {blo_PER }}$ are the metabolic rates of permethrin in liver, GI tract, and blood, respectively. Because the amounts were expressed in $\mathrm{mg}$, the amount of metabolites produced was multiplied by the ratio of the molecular weights (MW). Cis- and trans-DCCA were assumed to be formed only in the liver as hepatic metabolism is found to be the predominant mode of metabolic pathway (Crow et al., 2007).

The schematic of the models are represented in Figure 1 and the equations are provided in Supplemental material.

\section{Model parameterization}

The physiological parameters are summarized in Table 1 and were either measured in the rats used in this study (volumes) or were obtained from the literature (Waites, 1991; Brown et al., 1997; Schoeffner et al., 1999). All the permethrin-specific parameters were estimated using the measured concentrations in the tissues and fluids except for two metabolic rates, blood and intestinal, as our experiments were not designed to estimate the metabolic rates in all three metabolic sites (liver, intestine and blood). Since experiments in vitro have shown the degree of metabolism in blood and intestinal tissue to be much lower than in liver (Crow et al., 2007), the blood and intestinal metabolic rates were fixed to appropriate numerical values. The blood and intestinal metabolic rates were thus fixed to $0.07 \mathrm{~L} / \mathrm{h} / \mathrm{kg}$ and $0.04 \mathrm{~L} / \mathrm{h} / \mathrm{kg}$ for cis-permethrin and to $0.29 \mathrm{~L} / \mathrm{h} / \mathrm{kg}$ and $0.3 \mathrm{~L} / \mathrm{h} / \mathrm{kg}$ for trans- 
permethrin, respectively. These rates were calculated based on the extrapolation to in vivo of the in vitro results obtained in whole serum (Crow et al., 2007) and intestinal microsomes of rats (Nakamura et al., 2007). The study conducted by Crow et al. (2007) was used to specifically quantify metabolism in rat blood. The metabolic rate in blood for trans-permethrin was obtained by scaling the intrinsic clearance rate observed in rat serum (as the ratio of $V \max / \mathrm{Km}$; Vmax of $4.2 \mathrm{nmol} / \mathrm{min} / \mathrm{mL}$ serum and $\mathrm{Km}$ of $29.4 \mu \mathrm{M}$ ) to the volume of serum in blood (approximately $45 \%$ ) and to the blood volume in adult rats (74 mL/kg of BW) (Brown et al., 1997). The intrinsic clearance of cis-permethrin in blood was obtained by reducing the intrinsic clearance of the trans isomer by 4.3 fold, corresponding to the observed ratio of the specific activity of the two isomers in rat serum in the study by Crow et al. (2007). The in vivo intestinal intrinsic clearance of trans-permethrin was obtained by extrapolating the slope of the formation curve of the metabolite 3-phenoxybenzoic alcohol after $10 \mathrm{~min}$ of exposure (Nakamura et al., 2007). The physiological parameters, $2.2 \mathrm{mg}$ of protein/g of intestines (Martignoni et al., 2006) and $2.7 \mathrm{~g} / \mathrm{kg}$ of BW for the weight of the intestines (Brown et al., 1997), were used as scaling factors. A ratio of 8.6 was applied to derive the intestinal intrinsic clearance of cis-permethrin as observed by Nakamura et al. (2007) between the rates of formation of 3-phenoxybenzoic alcohol from the two isomers.

The other parameters specific to permethrin and its metabolites were estimated simultaneously in a Bayesian framework. In such analysis, each parameter is considered as a random variable and a prior probability distribution reflecting the prior knowledge on the parameter's values is assigned to each parameter. The Bayes theorem was used to update the prior distribution using the experimental data obtained in our current study (specifically, the measured concentrations of each chemicals in various tissues and fluids) in order to derive a posterior distribution that can then be viewed as a combination of the prior knowledge and the information contained in the experimental data (Gelman et al., 1996; Davis et al., 2012). The prior distributions assigned to the parameters to be estimated are summarized in Table 2 and Table 3. All parameters were assumed to follow a truncated normal distribution. In vitro experiments on metabolism and the previously published toxicokinetic models were used as prior information in our analysis. The means of the prior distributions for the partition coefficients, the 
rate constants and the permeability coefficients were defined according to the values reported in previous PBPK models for permethrin and deltamethrin (Mirfazaelian et al., 2006; Tornero-Velez et al., 2012). The coefficients of variation were fixed to be $50 \%$ for partition coefficients and rate constants, and to be $100 \%$ for the permeability coefficients because of higher uncertainty. The means of the prior distributions for the intrinsic clearance in liver were set to $3.47 \mathrm{~L} / \mathrm{h} / \mathrm{kg} \mathrm{BW}$ and 9.86 $\mathrm{L} / \mathrm{h} / \mathrm{kg} \mathrm{BW}$ for cis- and trans-permethrin, respectively. These values were obtained by extrapolating in vitro clearances observed in human hepatic microsomes (Scollon et al., 2009). The ratio of $\operatorname{Vmax} / \mathrm{Km}$ was scaled to the in vivo hepatic intrinsic clearance by using the following physiological parameters, i.e., $45 \mathrm{mg}$ of microsomal protein/g of liver (Houston, 1994) and $34 \mathrm{~g}$ of liver $/ \mathrm{kg}$ of BW (Brown et al., 1997).

Some of the parameters were kept fixed as they cannot be estimated from the measured concentrations in the tissues and fluids sampled in this study. The partition coefficients of both isomers of permethrin in GI tract $\left(P C_{g i}\right)$ and in rapidly perfused tissues $\left(P C_{r p}\right)$ were set to the estimated value of the partition coefficient in kidney $\left(P C_{k i d}\right)$. Only for trans-permethrin, the partition coefficient in liver $\left(P C_{l i v}\right)$ was assumed to be equal to $P C_{k i d}$ and the one in testes $\left(P C_{t e s}\right)$ equal to the one in brain $\left(P C_{b r a}\right)$ since the compounds were not detected in these organs. The permeability coefficient of testes $\left(P A_{t e s}\right)$ for transpermethrin was assumed to be three times lower than the one estimated in brain $\left(P A_{b r a}\right)$ based on the ratio of the permeability coefficients estimated for $c i s$-permethrin in these organs.

For metabolites, uniform distributions were assigned to the fractions of metabolites formed from the total intrinsic clearance of each isomer of permethrin. The prior distributions of the partition and permeability coefficients and the fecal elimination rates of DCCA were similar to those of permethrin. The mean value of the urine excretion rate of the metabolites was set to be the inverse of $16.5 \mathrm{~h}$, corresponding to the mean half-life of the urinary elimination of the metabolites after an ingestion of cypermethrin (Woollen et al., 1992).

The likelihood on the data was assumed to follow a lognormal distribution with $15 \%$ of error for all concentrations except in blood for which $5 \%$ of error was needed to reproduce adequately the observed kinetics. The calibration of the PBPK model was performed using the average of the 
concentrations obtained from the group of 4 rats euthanized at a specific time point. Markov Chain Monte Carlo methods were used to estimate the posterior probability distributions using MCSim software (Bois and Mazle, 1997). Three independent Markov chains of 10,000 iterations were run and one in two of the last 5,000 iterations were recorded. A stable posterior distribution was assumed to be reached when the convergence criterion $\hat{R}$ was below 1.1 .

Evaluation of the confidence in the predictions performed by the extended PBPK model

Available data on permethrin in the literature (Tornero-Velez et al., 2012) were used to assess the ability of the set of estimated values of parameters to predict concentrations in other experimental conditions. In their study, Tornero-Velez et al. (2012) performed in vivo experiments in rats for a mixture (40:60) of cis- and trans-permethrin at two oral doses, $1 \mathrm{mg} / \mathrm{kg}$ and $10 \mathrm{mg} / \mathrm{kg}$ of total permethrin, and measured the concentrations of permethrin isomers in blood and three tissues (liver, fat and brain). The extended PBPK model was run with these doses as input and their predictions were compared to the measured concentrations. Due to the observed differences in the absorption phase between the two experimental studies, two assumptions were tested using our model: 1) the PBPK model calibrated in the current study was used as is to predict the literature data; 2) the absorption parameters $\left(K_{s i}\right.$ and $\left.K_{\text {int }}\right)$ were set to the values used by previous PBPK model of pyrethroids (Mirfazaelian et al., 2006; Tornero-Velez et al., 2012) and all the other parameters were set to the estimates obtained in our study. 


\section{Results}

Observed toxicokinetics of cis- and trans-permethrin and metabolites

Both cis- and trans-permethrin were detected in blood, feces and all tissues (liver, muscle, kidneys, testes, brain and fat) at all time points. The kinetic profiles of the parent compounds in blood and in tissues are presented in Figures 2. However the levels of trans-permethrin were below the LOQ in liver and testes, and only the samples collected at a single time point of 1 hour in the kidneys were above this limit. The toxicokinetic profiles of the cis and trans isomers were very similar and the levels of cis-permethrin in all organs were always higher than that of trans-permethrin. The kinetic profiles of the isomers observed in blood, liver and kidneys were similar: a rapid distribution in the tissues with the observed times at maximal concentration between $1 \mathrm{~h}$ and $2 \mathrm{~h}$ and a fast elimination of the compounds in blood with a half-life of about $4.2 \mathrm{~h}$ for trans-permethrin and that of $1.5 \mathrm{~h}$ in the first phase of elimination of the cis isomer (Table 4). A second phase of elimination for cis-permethrin was observed in the blood and liver, with a half-life $\left(T_{1 / 2} \beta\right)$ of $3.3 \mathrm{~h}$ and $11.7 \mathrm{~h}$, respectively, suggesting a slower elimination of this isomer. Due to the relatively low number of detectable data points in liver (2) in the second phase of elimination, the estimated half-life $T_{1 / 2} \beta$ is affected by uncertainties and should be considered accordingly. As reported in previous studies, a slow diffusion of permethrin was observed in tissues such as fat, muscle and organs that have a physiological barrier like brain and testes. The values of the AUC computed using observed concentrations $\left(\mathrm{AUC}_{\mathrm{obs}}\right)$ are summarized in Table 5 and confirm the kinetic profiles, also reflected in the values of half-life. The 65-fold higher $\mathrm{AUC}_{\mathrm{obs}}$ in the fat tissue in comparison to that in blood emphasized the degree of accumulation of the trans isomer in this tissue. Similarly, the ratio of $\mathrm{AUC}_{\mathrm{obs}}$ in organs to blood for cis-permethrin is greater than one, ranging from 1.7 in muscle to 304 in fat.

The toxicokinetics of permethrin metabolites are presented in Figure 3 and Figure 4. The concentrations of metabolites from the trans-isomer are consistently much higher than the ones of the cis-permethrin, which are in the good agreement with the observed kinetic of the parent isomers. The formation of the metabolites is rapid with the quantification of $c i$-DCCA and trans-DCCA in blood 
and liver as early as 30 mins after the administration of the permethrin isomers. The concentrations in DCCA reach a peak at $5 \mathrm{~h}$ in the liver (Figure 3).

A delay of $2.5 \mathrm{~h}$ is observed in the times to reach maximal concentration between the parent compounds and its metabolites. The elimination of DCCA from blood and liver tissue, especially that of trans-DCCA, is slower compared to the rate of elimination of permethrin. The elimination of transDCCA is biphasic in nature in both the blood and liver tissue, with half-lives of $12.0 \mathrm{~h}$ and $30.1 \mathrm{~h}$ for each subsequent phase in the blood (Table 4). An accumulation of both isomers of DCCA is observed in liver, as confirmed by the high value of $\mathrm{AUC}_{\mathrm{obs}}$ computed to be $245.8 \mu \mathrm{g} . \mathrm{h} / \mathrm{mL}$ for trans-DCCA. The excretion of metabolites in urine is rapid, with a completed excretion after $24 \mathrm{~h}$ and a high recovery of 4'OH-PBA compared to the two other metabolites.

The linearity of the dose in permethrin was evaluated by comparing the measured concentrations in isomers of permethrin to the ones previously published in blood, liver, brain and fat of rats exposed to a mixture of isomers cis/trans (40:60) at 1 and $10 \mathrm{mg} / \mathrm{kg}$. For both isomers, the normalized concentrations at the doses of 1,10 and $25 \mathrm{mg} / \mathrm{kg}$ present similar profiles for the uptake and the elimination of permethrin. The three datasets supported the linearity of the dose for the tested organs/fluids for cis-permethrin. For trans-permethrin, we observed a slower elimination at the dose of $25 \mathrm{mg} / \mathrm{kg}$ in blood and fat, which may suggest a potential saturation at this highest dose of transpermethrin. However, in brain, the normalized concentrations of trans-permethrin are similar at the three dosages.

\section{Calibration of the extended PBPK models}

The extended PBPK models were calibrated to the measured concentrations of cis- and transpermethrin, and the metabolites. The values of the convergence criterion $\hat{R}$ computed for all parameters ranged between 1.0 and 1.1 indicating that the convergence was reached. The posterior distributions of the estimated parameters are reported in Table 2 and Table 3. All the posterior distributions showed coefficients of variation under $20 \%$. As expected, the coefficients of variation were higher for parameters related to tissues such as slowly perfused tissues for which no experimental data was available. Even if less kinetic data were available for metabolites compared to 
permethrin, the estimated posterior distributions of parameters related to DCCA, 3-PBA, and 4'-OHPBA were narrowed, especially for the fraction of metabolites formed from the total clearance of permethrin. Among all parameters, the fraction of metabolites formed $\left(F_{r a c} c_{m e t}\right)$ was the sole one to be assigned to a prior uniform distribution. Following model calibration, the estimated coefficient of variation for $\mathrm{Frac}_{\text {met }}$ for each metabolite was under 10\%, indicating that the measured data on metabolites in urine were informative.

\section{Toxicokinetic profiles of cis- and trans-permethrin}

The estimated concentrations of permethrin isomers using the PBPK model were in good agreement with the observed concentrations for all the fluids and organs (Figure 2). The estimated area under the curve $\left(\mathrm{AUC}_{\mathrm{est}}\right)$ was comparable to the observed $\mathrm{AUC}_{\mathrm{obs}}$ and differed only by $6 \%$ in kidneys to $21 \%$ in blood for cis-permethrin, and by $5 \%$ in brain to $26 \%$ in fat for trans-permethrin (Table 5). Based on the $\mathrm{AUC}_{\mathrm{est}}$, the internal exposure of cis-permethrin is estimated to be higher than that for transpermethrin, by a 2.8- to a 15.6-factor in blood and kidneys, respectively. For brain, fat, kidneys and liver, this factor exceeded 7. Such differences in tissue distribution trends were reflected in the model estimated values of the tissue partition coefficients. It should be noted that for trans-permethrin, no data were available in the liver and testes; only one time point was available in the kidneys with all other samples below the LOQ. These results were then affected by uncertainties and the $\mathrm{AUC}_{\text {est }}$ could even be lower for trans-permethrin especially in testes and liver.

Both cis and trans isomers were rapidly absorbed in the intestines, and also rapidly eliminated in liver. The estimated values for the rate of the intestinal absorption $\left(K_{\text {int }}\right)$ for the cis and trans isomers are at $0.52 \mathrm{~h}^{-1}$ and $1.3 \mathrm{~h}^{-1}$, respectively. The in vivo hepatic clearances were estimated at $5.7 \mathrm{~L} / \mathrm{h} / \mathrm{kg}$ (confidence interval at $95 \%[5.0 ; 6.4]$ ) and $2.4 \mathrm{~L} / \mathrm{h} / \mathrm{kg}$ (confidence interval at $95 \%[2.2 ; 2.7]$ ) for trans- and cis-permethrin respectively. The 2.4-ratio estimated between these two clearances is in the same range as that of the 2.8-ratio estimated between the in vitro hepatic clearances of isomers of permethrin measured using rat hepatic microsomes (Scollon et al., 2009) but slightly lower compared to that observed (3.9-ratio) in rats exposed to a mixture of the two permethrin's isomers (TorneroVelez et al., 2012). 
Both cis and trans isomers accumulated in fat with a partition coefficient $\left(P C_{f a t}\right)$ value of 225 and 76 , respectively, and a high half-life value of $124 \mathrm{~h}$ and $24 \mathrm{~h}$, respectively. These results are typical of the kinetics of pyrethroids in lipophilic tissues. However, our calibrated PBPK model over-estimated the concentrations in trans-permethrin in fat. While several assumptions were tested for the model calibration to reduce the over-estimation, no satisfactory result was achieved without diminishing the predictions accuracy in other organs and fluids. This can be a consequence of the absence of accumulation of permethrin in the muscle. The partition coefficients in muscle were around 1 and the permeability was higher compared to the values estimated for fat, brain and testes.

No parent compound was detected in urine which is consistent with previous observations of Leng et al. (2005). Complete excretion of cis- and trans-permethrin into feces $24 \mathrm{~h}$ after the administration, with a total recovery of $39 \%$ (for the dose of $4.6 \mathrm{mg}$ for both isomers) after 6 days, was consistent with the estimated oral bioavaibility of $61 \%$ for permethrin as observed by Anadon et al. (1991).

Toxicokinetic profiles of the metabolites cis-DCCA, trans-DCCA, 3-PBA and 4'-OH-PBA

The estimated posterior distributions of the model parameters related to metabolites are summarized in Table 3. Estimated values of parameters for DCCA allowed for satisfactory model predictions of the DCCA kinetics in blood and liver (Figure 3). Cis- and trans-permethrin were mainly transformed into metabolites DCCA and 4'-OH-PBA. The estimated metabolite fraction for DCCA and 4'-OHPBA, calculated as formed from the total clearance of each isomer of permethrin, is 0.22 and 0.29 , respectively, following an exposure to cis-permethrin, and 0.52 and 0.45 after an exposure to transpermethrin. With an estimated metabolite fraction 10 to 40 times lower, 3-PBA was produced to a lesser extent. By applying these fractional factors to the liver clearances of permethrin, the rates of formation of DCCA, 4'-OH-PBA and 3-PBA in rats were estimated at $0.53,0.70$, and $0.01 \mathrm{~L} / \mathrm{h} / \mathrm{kg}$, respectively, after an exposure to cis-permethrin and at $2.96,2.57$ and $0.27 \mathrm{~L} / \mathrm{h} / \mathrm{kg}$ after an exposure to trans-permethrin. Due to the higher clearance of trans-permethrin, trans-DCCA was recovered in higher amount in blood and liver than cis-DCCA, with an $\mathrm{AUC}_{\text {est }}$ ratio trans:cis of 5 in liver and 8 in blood (Table 5). Mainly formed in the liver, cis- and trans-DCCA both accumulated in this organ and 
the values of partition coefficients of cis-DCCA and trans-DCCA were estimated to be 6.3 and 4.4, respectively.

The predictions of metabolites amounts in urine are in a good agreement with the observations (Figure 4). The excretion of the metabolites was completed in the first 24 hours in urine and 48 hours in feces. For both isomers, 4'-OH-PBA was the most recovered metabolites in urine, with a 5- and a 10-factor compared respectively to cis-DCCA and 3-PBA in the case of cis-permethrin. DCCA was mainly excreted in feces. $76 \%$ of cis-DCCA and 62\% of trans-DCCA of the total DCCA eliminated for each isomer was recovered in feces. In feces, 3-PBA was not detected. Gaughan et al. (1977) observed however that both the metabolites DCCA and 3-PBA were in a largest amount in urine compared to feces, after the oral ingestion of radiolabeled cis or trans-permethrin.

\section{Model verification}

The extended PBPK model and the estimated values of model parameters for both isomers were used to simulate the observed concentrations of permethrin isomers in blood, brain, liver and fat after the co-administration of both isomers at 1 and $10 \mathrm{mg} / \mathrm{kg}$ (cis/trans 40:60) (Tornero-Velez et al., 2012). The model predictions in comparison to the observed data used for model evaluation are represented in Figure 5.

The toxicokinetic profiles predicted with the calibrated extended PBPK model (grey curves on Figure 5) were frequently not in good agreement with observed data. Specifically, the concentrations in the elimination phase of permethrin in organs were over-predicted and the ones in the absorption phase were markedly under-predicted in blood, liver and brain, between the data and model predictions. The extended model was further evaluated by adopting the absorption parameters values used in the model developed for similar pyrethroids (Mirfazaelian et al., 2006), i.e., the rate constant for the stomach-intestine transfer $\left(K_{s i}\right)$ and the intestinal absorption $\left(K_{\text {int }}\right)$ were set to $0.7 \mathrm{~h}^{-1}$ and $0.9 \mathrm{~h}^{-}$ ${ }^{1}$, respectively, for both isomers (black curves on Figure 5). Our originally estimated values for these parameters were quite different according to the isomer with a lower rate of the intestinal absorption $\left(K_{\text {int }}\right)$ of $0.5 \mathrm{~h}^{-1}$ for cis-permethrin and a higher rate of $1.3 \mathrm{~h}^{-1}$ for trans-permethrin. Using these modified values for the absorption phase allowed for obtaining comparable model predictions to the 
experimental data, especially for cis-permethrin. The predicted toxicokinetic profiles of transpermethrin in blood and liver were similar to the trend in the observed concentrations even if there was a remaining degree of over-prediction. The modifications impacted less the cis-permethrin toxicokinetics compared to the trans isomer ones. In its final calibrated form, the extended PBPK model correctly reproduced the observed concentrations in blood and 3 tissues (liver, brain and fat) measured after the co-administration of a mixture of permethrin isomers (ratio 40:60) to rats. Since no specific model was added to the extended PBPK model to account of the individual versus isomers mixture exposure scenario of exposure, these results could also suggest that no metabolic interaction in liver or in blood seemed to occur or were observable in vivo at the ratio of 40:60 of permethrin isomers. These results are also supported by the fact that the co-incubation of both isomers would lead to a decrease by $39 \%$ of the in vivo hepatic clearance of trans-permethrin, as observed in the in vitro interaction study performed by Scollon et al. (2009). If this modification of the clearance was applied here, the consequences will be to increase the levels of trans-permethrin in the organs and then the increase the over-prediction of our model. 


\section{Discussion}

Population is exposed to pyrethroids, which was confirmed by a frequent recovery of the metabolites of these insecticides in the human urine during biomonitoring studies. Urinary metabolites like 3-PBA and DCCA are known to be biomarkers of exposure to pyrethroids, due to the short time of residence of the parent compound in the body. Since the toxic properties of pyrethroids are directly related to the parent compound, a proper characterization of the kinetic of permethrin in the body is required. The development of a PBPK model including both the active compound and the ones considered as biomarkers of exposure was deemed relevant. The existence of different isomeric forms of permethrin and the documented metabolic interaction between them warrants the need for assessing the kinetic of each isomer of permethrin separately. We therefore proposed to adapt a former PBPK for permethrin in rats (Tornero-Velez et al., 2012) to the two major isomers of permethrin (cis and trans) separately and further extend it by including models for the corresponding urinary metabolites, 3-PBA, DCCA, and 4'-OH-PBA. The free form of metabolites of pyrethroids is commonly measured in biomonitoring studies (Heudorf et al., 2006; Morgan, 2012); therefore this form was retained in this study to facilitate future uses of the developed PBPK model in a risk assessment context.

The PBPK model previously developed for deltamethrin and permethrin (Mirfazaelian et al., 2006; Tornero-Velez et al., 2012) was extended to describe the kinetics of the metabolites (DCCA, 3-PBA and 4'OH-PBA), and also to include additional information on tissues such as muscle, testes and kidneys in rats that were not investigated previously. Whereas the prior published PBPK models of pyrethroids were calibrated by visual fitting, the extended model was fitted to the experimental data in a Bayesian framework. This approach consists of assigning prior distributions to all parameters to be estimated and updating these distributions with the experimental data and the PBPK model through the Bayes theorem. Bayesian calibration has been successfully applied to PBPK models and has shown to be able to inform parameters related to the major ADME processes, such as metabolic rates (Brochot and Bois, 2005; Brochot et al., 2007). In such complex calibration processes where data have been collected in different tissues or have been generated in different studies, an automatic 
calibration approach such as the one employed here should be preferable to not overweight some data (that are subject to experimental error) and constrain the model fitting.

The calibration of the extended model was performed simultaneously using experimental data in all the measured fluids and organs and for all the chemical species relative to a specific isomer. The estimated kinetic profiles of both isomers were in good agreement with the data and consistent with observations in previous studies (Gaughan et al., 1977; Anadon et al., 1991; Tornero-Velez et al., 2012). The kinetic profile comprised of a rapid absorption, a large accumulation in fat and a longer residence time for the cis isomer compared to the trans one. The quantification of permethrin in additional organs such as the muscle, testes and kidneys and its detection in the brain indicated that permethrin does cross the blood-testis barrier and it could pose an issue during critical time windows for developmental effects. The kidney tissue was found to behave like liver, making it a good surrogate for richly perfused tissues. Our results also underlined that permethrin does not accumulate in muscle, although it distribution was always associated with a high tissue:blood partition coefficient values, computed from experiments with 10-day-old rats exposed to deltamethrin (Mirfazaelian et al., 2006; Tornero-Velez et al., 2012). However muscle still remains a major compartment of the PBPK model since it comprises a large proportion (40\%) of the body mass. Our model was however not able to reproduce correctly the trans-permethrin kinetics in fat and over-estimated the concentrations for the initial few hours after the exposure. No optimization was performed to improve the model fit in fat because the Bayesian framework ensures that the fit to the data was made simultaneously in all compartments with the same weight, without favoring a specific organ as the site of metabolism. This over-estimation can be a result of the lack of detection of trans-permethrin in several tissues (liver, kidneys, and testes) that can lead an under-estimation of the levels in those organs. The absence of liver concentrations above the LOQ for trans-permethrin also increase the uncertainty in the hepatic clearance compared to the cis isomer. A ratio of 2.4 was estimated for the values of the hepatic clearance of the cis and trans isomers, which is similar to the estimated ratio of 2.8 calculated from in vitro hepatic clearance measurements for isomers of permethrin using rat hepatic microsomes (Scollon et al., 2009). The estimated values of the hepatic clearance of the isomers cis and trans are in 
the same range but slightly lower than the ones obtained by extrapolating the in vitro clearances observed in the hepatic microsomes to in vivo intrinsic hepatic clearance.

The toxicokinetics of the urinary metabolites commonly used as biomarkers of exposure (DCCA and 3-PBA) were also investigated to characterize the timing of their excretion after an exposure. Both free form and newly free form after cleavage were measured without distinction in this study. Sufficient data were available to derive a simplified PBPK model for DCCA (3 compartments), and empirical models were defined for 3-PBA and 4'-OH-PBA. We chose a physiological model for DCCA in order to have available a model that could easily be extrapolated to humans and sensitive populations like children compared to empirical models. All of these models were then linked to the PBPK model of the parent compounds via the metabolic sites. The metabolites data were well reproduced by the models, and similar rates of formation were estimated for DCCA and 4'-OH-PBA that were significantly higher than the one for 3-PBA. Our results also pointed out that DCCA was more persistent in blood and liver than the parent compounds, and was still detected in liver 6 days after the administration for the trans isomer. However the urinary excretion was almost complete 2 days after the exposure. The amounts of metabolites 4'-OH-PBA, DCCA and 3-PBA as detected in urine at the end of the excretion when represented as a proportion of the sum of amounts of the three metabolites were $84 \%, 14 \%$ and $2 \%$, respectively, for the cis isomer and $70 \%, 23 \%$ and $7 \%$, respectively, for the trans isomer. Gaughan et al. (1977) had previously reported on the high recovery of 4'-OH-PBA of $43 \%$ for trans-permethrin and $29 \%$ for cis-permethrin over a large number of metabolites (compared to the 3 of our study) after administration of permethrin radiolabeled on the alcohol moiety.

Once the extended PBPK model was calibrated, the ability of our estimated set of values of parameters to reproduce the kinetic profiles of permethrin obtained in another study context was verified by using published data on isomers of permethrin in rats (Tornero-Velez et al., 2012). Initial evaluation led to simulations that were not in good agreement with the published experimental concentrations partly due to differences in the absorption process. As underlined by Mirfazaelian et al. (2006) based on the results of a sensitivity analysis conducted on a PBPK model for deltamethrin, 
blood and brain concentrations were very sensitive to the value of the stomach-intestinal constant $\left(K_{s i}\right)$ and intestinal constant $\left(K_{\text {int }}\right)$. Since a shift in the kinetic profile was observed in the absorption phase between the two studies, the extended PBPK model was simulated using the absorption specific parameters commonly utilized for pyrethroids like deltamethrin and permethrin (Mirfazaelian et al., 2006). With the estimated set of values of parameters and the absorption parameters fixed, the extended PBPK model better predicted the published concentrations (Tornero-Velez et al., 2012), especially for cis-permethrin, the most toxic isomer (Lawrence and Casida, 1982; Soderlund et al., 2002). However, the over-prediction in fat was recovered for trans-permethrin at the high dose of 6 $\mathrm{mg} / \mathrm{kg}$, which is consistent with the results of the calibration of the extended PBPK model. Thus, the predictive ability of the extended and calibrated PBPK model was verified for the disposition of the parent compound. The same approach was not performed for the part of the model related to the metabolites due to a lack of data for these compounds in rats in the literature. By verifying the performance of the extended model and given the similar internal exposure of permethrin isomers individually or in a mixture, a potential lack of an in vivo metabolic interaction between the two permethrin isomers at the ratio 40:60 was identified. However, this hypothesis needs to be evaluated by a proper interaction study in rats, at various ratios. Recently, a similar study was performed on human hepatocytes and highlighted that the interaction was negligible at the ratio 50:50 of isomers but became substantial (50\% of interaction) at a ratio 10 times higher (Willemin et al., 2015).

The results of our study are promising in terms of exposure assessment to permethrin and potentially to pyrethroids family. A generic structure of PBPK model for pyrethroids sharing a similar structure as permethrin seems to appear, which includes the description of the kinetic of the insecticide in fat and the sensitive organs like brain and testes. Then, the extended PBPK model developed in this study can be extrapolated to humans for the quantification of the internal exposure, especially in sensitive populations like children, by including data in humans like the recent in vitro results on Caco-2 cells informing on the rate of oral absorption (Zastre et al., 2013), or on microsomes and hepatocytes quantifying the hepatic metabolism (Scollon et al., 2009; Willemin et al., 2015). With the description of the kinetic of the biomarkers of exposure under the chemical form measured in biomonitoring 
studies, the extended PBPK model can be also used in a reverse dosimetry context to assess the external exposure of human populations (Ulaszewska et al., 2012; Wetmore et al., 2012; Wei et al., 2013; Zeman et al., 2013; Cote et al., 2014; Huizer et al., 2014). These approaches are based on the interpretation of biomonitoring data using toxicokinetic models and individual characteristics to estimate the population or individual exposure (Clewell et al., 2008). Once the relevant population exposure is estimated, the extended PBPK model can be used to predict the relevant internal dosimetry of the compounds during sensitive life-stages, which will allow a better assessment of their impacts on the public health (Verner et al., 2010). Performing such approach on the rat PBPK model could have confirmed the quality of predictions, but no dataset including the kinetic of both parent compound and metabolites was available in the literature at the time of this study. However, the challenge in reverse dosimetry for permethrin and pyrethroids remains to be the issue of mixtures and their potential interactions. Pyrethroids share metabolic pathways and common metabolites that can make the exposure assessment quite complicated, for example, what amount of metabolites can be attributed to a specific parent compound. Our study allowed the description of the kinetic of each isomer of permethrin separately in vivo, but, associated with a better understanding of the frame of the interactions between the different isomers and pyrethroids, our model could contribute to a simplification of the future exposure assessments to mixture of pyrethroids, a more realistic scenario, with PBPK models.

\section{Aknowledgememts}

This work was supported by the foundation of Université de Technologie de Compiègne "La Fondation UTC pour l'Innovation" [ToxOnChip project] and the French Ministry of Ecology and Sustainable Development [Program 190]. 


\section{References}

Anadon, A., Martinezlarranaga, M.R., Diaz, M.J., Bringas, P., 1991. Toxicokinetics of Permethrin in the Rat. Toxicol Appl Pharm 110, 1-8.

Barr, D.B., Baker, S.E., Whitehead, R.D., Wong, L., Needham, L.L., 2010. Urinary Concentrations of Pyrethroid Metabolites in the General US Population, NHANES 1999-2002. Epidemiology 19, S192-S193.

Beal, S.L., 2001. Ways to fit a PK model with some data below the quantification limit. J Pharmacokinet Pharmacodyn 28, 481-504.

Bois, F.Y., Mazle, D.R., 1997. MCSim: A Monte Carlo Simulation Program. J Stat Softw 2.

Bradberry, S.M., Cage, S.A., Proudfoot, A.T., Vale, J.A., 2005. Poisoning due to pyrethroids. Toxicol rev 24, 93-106.

Brochot, C., Bois, F.Y., 2005. Use of a chemical probe to increase safety for human volunteers in toxicokinetic studies. Risk Analysis 25, 1559-1571.

Brochot, C., Smith, T.J., Bois, F.Y., 2007. Development of a physiologically based toxicokinetic model for butadiene and four major metabolites in humans: global sensitivity analysis for experimental design issues. Chemico-biological interactions 167, 168-183.

Brown, R.P., Delp, M.D., Lindstedt, S.L., Rhomberg, L.R., Beliles, R.P., 1997. Physiological parameter values for physiologically based pharmacokinetic models. Toxicol Ind Health 13, 407-484.

Clewell, H.J., Tan, Y.M., Campbell, J.L., Andersen, M.E., 2008. Quantitative interpretation of human biomonitoring data. Toxicology and applied pharmacology 231, 122-133.

Cote, J., Bonvalot, Y., Carrier, G., Lapointe, C., Fuhr, U., Tomalik-Scharte, D., Wachall, B., Bouchard, M., 2014. A novel toxicokinetic modeling of cypermethrin and permethrin and their metabolites in humans for dose reconstruction from biomarker data. PLoS One 9, e88517.

Crow, J.A., Borazjani, A., Potter, P.M., Ross, M.K., 2007. Hydrolysis of pyrethroids by human and rat tissues: Examination of intestinal, liver and serum carboxylesterases. Toxicol Appl Pharm 221, 1-12.

Davis, J., Tornero-Velez, R., Setzer, R.W., 2012. Computational Approaches for Developing Informative Prior Distributions for Bayesian Calibration of PBPK Models In Knaak, J.B., Timchalk, C., Tornero Velez, R., (Eds.), Parameters for Pesticide QSAR and PBPK/PD Models for Human Risk Assessment. ACS Publications, Washington, pp.

Egerer, E., Rossbach, B., Muttray, A., Schneider, M., Letzel, S., 2004. Biomonitoring of pyrethroid metabolites in environmental medicine. Umweltmed Forsh Prax 9.

Flannigan, S.A., Tucker, S.B., Key, M.M., Ross, C.E., Fairchild, E.J., Grimes, B.A., Harrist, R.B., 1985. Synthetic Pyrethroid Insecticides - a Dermatological Evaluation. Br J Ind Med 42, 363 372.

Gaughan, L.C., Unai, T., Casida, J.E., 1977. Permethrin Metabolism in Rats. J Agric Food Chem 25, 9-17.

Gelman, A., Meng, X.L., Stern, H., 1996. Posterior predictive assessment of model fitness via realized discrepancies. Stat Sinica 6, 733-760.

Godin, S.J., DeVito, M.J., Hughes, M.F., Ross, D.G., Scollon, E.J., Starr, J.M., Setzer, R.W., Conolly, R.B., Tornero-Velez, R., 2010. Physiologically Based Pharmacokinetic Modeling of Deltamethrin: Development of a Rat and Human Diffusion-Limited Model. Toxicol Sci 115, 330-343.

Gotoh, Y., Kawakami, M., Matsumoto, N., Okada, Y., 1998. Permethrin emulsion ingestion: Clinical manifestations and clearance of isomers. J Toxicol-Clin Toxic 36, 57-61.

He, F.S., Wang, S.G., Liu, L.H., Chen, S.Y., Zhang, Z.W., Sun, J.X., 1989. Clinical Manifestations and Diagnosis of Acute Pyrethroid Poisoning. Arch Toxicol 63, 54-58.

Heudorf, U., Butte, W., Schulz, C., Angerer, J., 2006. Reference values for metabolites of pyrethroid and organophosphorous insecticides in urine for human biomonitoring in environmental medicine. Int J Hyg Envir Heal 209, 293-299. 
Houston, J.B., 1994. Utility of in-Vitro Drug-Metabolism Data in Predicting in-Vivo MetabolicClearance. Biochem Pharmacol 47, 1469-1479.

Huizer, D., Ragas, A.M., Oldenkamp, R., van Rooij, J.G., Huijbregts, M.A., 2014. Uncertainty and variability in the exposure reconstruction of chemical incidents--the case of acrylonitrile. Toxicology letters 231, 337-343.

Imai, K., Yoshinaga, J., Yoshikane, M., Shiraishi, H., Mieno, M.N., Yoshiike, M., Nozawa, S., Iwamoto, T., 2014. Pyrethroid insecticide exposure and semen quality of young Japanese men. Reprod Toxicol 43, 38-44.

InVS, 2013. Exposition de la population française aux substances chimiques de l'environnement. Tome 2 : Polychlorobiphényles et Pesticides. Institut de Veille Sanitaire, pp. 178.

Jin, Y.X., Liu, J.W., Wang, L.G., Chen, R.J., Zhou, C., Yang, Y.F., Liu, W.P., Fu, Z.W., 2012. Permethrin exposure during puberty has the potential to enantioselectively induce reproductive toxicity in mice. Environ Int 42, 144-151.

Kühn, K.H., Leng, G., Bucholski, K.A., Dunemann, L., Idel, H., 1996. Determination of pyrethroid metabolites in human urine by capillary gas chromatography-mass spectrometry. Chromatographia 43, 285-292.

Lawrence, L.J., Casida, J.E., 1982. Pyrethroid toxicology: Mouse intracerebral structure-toxicity relationships. Pesticide Biochemistry and Physiology 18, 9-14.

Le Grand, R., Dulaurent, S., Gaulier, J.M., Saint-Marcoux, F., Moesch, C., Lachatre, G., 2012. Simultaneous determination of five synthetic pyrethroid metabolites in urine by liquid chromatography-tandem mass spectrometry: Application to 39 persons without known exposure to pyrethroids. Toxicol Lett 210, 248-253.

Leng, G., Gries, W., 2005. Simultaneous determination of pyrethroid and pyrethrin metabolites in human urine by gas chromatography-high resolution mass spectrometry. J Chromatogr B 814, 285-294.

Lequesne, P.M., Maxwell, I.C., Butterworth, S.T.G., 1981. Transient Facial Sensory Symptoms Following Exposure to Synthetic Pyrethroids - a Clinical and Electro-Physiological Assessment. Neurotoxicology 2, 1-11.

Lestremau, F., Willemin, M.-E., Chatellier, C., Desmots, S., Brochot, C., 2014. Determination of cispermethrin, trans-permethrin and associated metabolites in rat blood and organs by gas chromatography-ion trap mass spectrometry. Anal Bioanal Chem 406, 3477-3487.

Martignoni, M., Groothuis, G., de Kanter, R., 2006. Comparison of mouse and rat cytochrome P450mediated metabolism in liver and intestine. Drug metabolism and disposition: the biological fate of chemicals 34, 1047-1054.

Meeker, J.D., Barr, D.B., Hauser, R., 2008. Human semen quality and sperm DNA damage in relation to urinary metabolites of pyrethroid insecticides. Hum Reprod 23, 1932-1940.

Mikata, K., Isobe, N., Kaneko, H., 2012. Biotransformation and enzymatic reactions of synthetic pyrethroids in mammals. Top curr chem 314, 113-135.

Mirfazaelian, A., Kim, K.B., Anand, S.S., Kim, H.J., Tornero-Velez, R., Bruckner, J.V., Fisher, J.W., 2006. Development of a physiologically based pharmacokinetic model for deltamethrin in the adult male Sprague-Dawley rat. Toxicol Sci 93, 432-442.

Morgan, M.K., 2012. Children's Exposures to Pyrethroid Insecticides at Home: A Review of Data Collected in Published Exposure Measurement Studies Conducted in the United States. Int J Environ Res Public Health 9, 2964-2985.

Nakamura, Y., Sugihara, K., Sone, T., Isobe, M., Ohta, S., Kitamura, S., 2007. The in vitro metabolism of a pyrethroid insecticide, permethrin, and its hydrolysis products in rats. Toxicology 235, 176-184.

Ross, M.K., Borazjani, A., Edwards, C.C., Potter, P.M., 2006. Hydrolytic metabolism of pyrethroids by human and other mammalian carboxylesterases. Biochem Pharmacol 71, 657-669.

Schoeffner, D.J., Warren, D.A., Muralidara, S., Bruckner, J.V., Simmons, J.E., 1999. Organ weights and fat volume in rats as a function of strain and age. J Toxicol Environ Health A 56, 449462 .

Scollon, E.J., Starr, J.M., Godin, S.J., DeVito, M.J., Hughes, M.F., 2009. In Vitro Metabolism of Pyrethroid Pesticides by Rat and Human Hepatic Microsomes and Cytochrome P450 Isoforms. Drug Metab Dispo 37, 221-228. 
Soderlund, D.M., 2012. Molecular mechanisms of pyrethroid insecticide neurotoxicity: recent advances. Arch Toxicol 86, 165-181.

Soderlund, D.M., Clark, J.M., Sheets, L.P., Mullin, L.S., Piccirillo, V.J., Sargent, D., Stevens, J.T., Weiner, M.L., 2002. Mechanisms of pyrethroid neurotoxicity: implications for cumulative risk assessment. Toxicology 171, 3-59.

Soucy, N.V., Parkinson, H.D., Sochaski, M.A., Borghoff, S.J., 2006. Kinetics of Genistein and Its Conjugated Metabolites in Pregnant Sprague-Dawley Rats Following Single and Repeated Genistein Administration. Toxicological Sciences 90, 230-240.

Stout, D.M., II, Bradham, K.D., Egeghy, P.P., Jones, P.A., Croghan, C.W., Ashley, P.A., Pinzer, E., Friedman, W., Brinkman, M.C., Nishioka, M.G., Cox, D.C., 2009. American Healthy Homes Survey: A National Study of Residential Pesticides Measured from Floor Wipes. Environ Sci Technol 43, 4294-4300.

Takaku, T., Mikata, K., Matsui, M., Nishioka, K., Isobe, N., Kaneko, H., 2011. In Vitro Metabolism of trans-Permethrin and Its Major Metabolites, PBalc and PBacid, in Humans. J Agric Food Chem 59, 5001-5005.

Tornero-Velez, R., Davis, J., Scollon, E.J., Starr, J.M., Setzer, R.W., Goldsmith, M.-R., Chang, D.T., Xue, J., Zartarian, V., DeVito, M.J., Hughes, M.F., 2012. A Pharmacokinetic Model of cisand trans-Permethrin Disposition in Rats and Humans With Aggregate Exposure Application. Toxicol Sci 130, 33-47.

Ueyama, J., Saito, I., Kamijima, M., 2010. Analysis and evaluation of pyrethroid exposure in human population based on biological monitoring of urinary pyrethroid metabolites. J Pestic Sci $\mathbf{3 5}$, 87-98.

Ulaszewska, M.M., Ciffroy, P., Tahraoui, F., Zeman, F.A., Capri, E., Brochot, C., 2012. Interpreting PCB levels in breast milk using a physiologically based pharmacokinetic model to reconstruct the dynamic exposure of Italian women. Journal of exposure science \& environmental epidemiology 22, 601-609.

US EPA, 2005. Overview of Permethrin Risk Assessment. U.S. Environmental Protection Agency, pp.

US EPA, 2011. Pesticides Industry Sales and Usage : 2006 and 2007 Market Estimates. U.S. Environmental Protection Agency, Washington, pp.

Verner, M.A., Plusquellec, P., Muckle, G., Ayotte, P., Dewailly, E., Jacobson, S.W., Jacobson, J.L., Charbonneau, M., Haddad, S., 2010. Alteration of infant attention and activity by polychlorinated biphenyls: unravelling critical windows of susceptibility using physiologically based pharmacokinetic modeling. Neurotoxicology 31, 424-431.

Verschoyle, R.D., Aldridge, W.N., 1980. Structure-Activity-Relationships of Some Pyrethroids in Rats. Arch Toxicol 45, 325-329.

Waites, G.M., 1991. Thermoregulation of the scrotum and testis: studies in animals and significance for man. Adv Exp Med Biol 286, 9-17.

Wei, B., Isukapalli, S.S., Weisel, C.P., 2013. Studying permethrin exposure in flight attendants using a physiologically based pharmacokinetic model. J Expo Sci Environ Epidemiol 23, 416-427.

Wetmore, B.A., Wambaugh, J.F., Ferguson, S.S., Sochaski, M.A., Rotroff, D.M., Freeman, K., Clewell, H.J., 3rd, Dix, D.J., Andersen, M.E., Houck, K.A., Allen, B., Judson, R.S., Singh, R., Kavlock, R.J., Richard, A.M., Thomas, R.S., 2012. Integration of dosimetry, exposure, and high-throughput screening data in chemical toxicity assessment. Toxicological sciences : an official journal of the Society of Toxicology 125, 157-174.

Willemin, M.E., Kadar, A., de Sousa, G., Leclerc, E., Rahmani, R., Brochot, C., 2015. In vitro human metabolism of permethrin isomers alone or as a mixture and the formation of the major metabolites in cryopreserved primary hepatocytes. Toxicol In Vitro 29, 803-812.

Wolansky, M.J., Harrill, J.A., 2008. Neurobehavioral toxicology of pyrethroid insecticides in adult animals: a critical review. Neurotoxicol Teratol 30, 55-78.

Woollen, B.H., Marsh, J.R., Laird, W.J.D., Lesser, J.E., 1992. The Metabolism of Cypermethrin in Man - Differences in Urinary Metabolite Profiles Following Oral and Dermal Administration. Xenobiotica 22, 983-991. 
Young, H.A., Meeker, J.D., Martenies, S.E., Figueroa, Z.I., Barr, D.B., Perry, M.J., 2013. Environmental exposure to pyrethroids and sperm sex chromosome disomy: a cross-sectional study. Environ Health 12.

Zastre, J., Dowd, C., Bruckner, J., Popovici, A., 2013. Lack of P-glycoprotein-mediated efflux and the potential involvement of an influx transport process contributing to the intestinal uptake of deltamethrin, cis-permethrin, and trans-permethrin. Toxicol Sci 136, 284-293.

Zeman, F.A., Boudet, C., Tack, K., Floch Barneaud, A., Brochot, C., Pery, A.R., Oleko, A., Vandentorren, S., 2013. Exposure assessment of phthalates in French pregnant women: results of the ELFE pilot study. International journal of hygiene and environmental health 216, 271-279.

Zhang, S.-Y., Ueyama, J., Ito, Y., Yanagiba, Y., Okamura, A., Kamijima, M., Nakajima, T., 2008. Permethrin may induce adult male mouse reproductive toxicity due to cis isomer not trans isomer. Toxicology 248, 136-141.

Zhang, S.Y., Ito, Y., Yamanoshita, O., Yanagiba, Y., Kobayashi, M., Taya, K., Li, C., Okamura, A., Miyata, M., Ueyama, J., Lee, C.H., Kamijima, M., Nakajima, T., 2007. Permethrin may disrupt testosterone biosynthesis via mitochondrial membrane damage of leydig cells in adult male mouse. Endocrinology 148, 3941-3949. 


\section{List of Figures}

Figure 1. PBPK model of cis- and trans-permethrin and their metabolites cis- and trans-DCCA, 3PBA and 4'-OH-PBA with an oral exposure. Distribution in brain, muscle, fat, testes and slowly perfused tissues of parent compounds and in rest of body of DCCA are limited by the diffusion and distribution in other organs by the flow. 3-PBA, DCCA, 4'-OH-PBA are formed in liver.

Figure 2. Measured concentrations (symbols) of cis-permethrin (cis-p) (- ) and trans-permethrin (trans-p) ( $\square$ ) and toxicokinetic profiles estimated with the PBPK model (solid lines) of cis-permethrin (一) and trans-permethrin (-) in blood, liver, kidney, brain, testes, muscle and fat in rats after an exposure to $25 \mathrm{mg} / \mathrm{kg}$ of cis or trans-permethrin. The grey dotted line (- - -) stands for the LOQ of permethrin.

Figure 3. Measured concentrations of cis-DCCA $(\mathbf{\Delta})$ and trans-DCCA $(\Delta)$ and toxicokinetic profiles estimated with the PBPK model of cis-DCCA ( - - and trans-DCCA ( - - in blood and liver in rats after an exposure to $25 \mathrm{mg} / \mathrm{kg}$ of cis or trans-permethrin. The grey solid line (-) stands for the

\section{LOQ of DCCA.}

Figure 4. Kinetics of observed amounts in the metabolites 4'-OH-PBA $(\diamond)$, DCCA $(\Delta)$ and 3-PBA (०) and estimated amounts in 4'-OH-PBA (..), DCCA ( - - ) and 3-PBA ( $~ . ~-~-)$ in urine in rats after an exposure to $25 \mathrm{mg} / \mathrm{kg}$ of cis or trans-permethrin. Closed symbols and black lines are related to cispermethrin (cis-p) and open symbols and grey lines to trans-permethrin (trans-p).

Figure 5. Observed concentrations in blood, liver, brain and fat after an oral dose of cis-permethrin at $0.4 \mathrm{mg} / \mathrm{kg}(\bullet)$ and $4 \mathrm{mg} / \mathrm{kg}(\bullet)$ and of trans-permethrin at $0.6 \mathrm{mg} / \mathrm{kg}(\square)$ and $6 \mathrm{mg} / \mathrm{kg}(\circ)$. The observed data are issued from the study of Tornero-Velez et al. (2012). The predicted concentrations from the values of parameters estimated with the extended PBPK model of permethrin and metabolites ( - ) and with the extended PBPK model with absorption rate fixed ( - ) are also represented. 

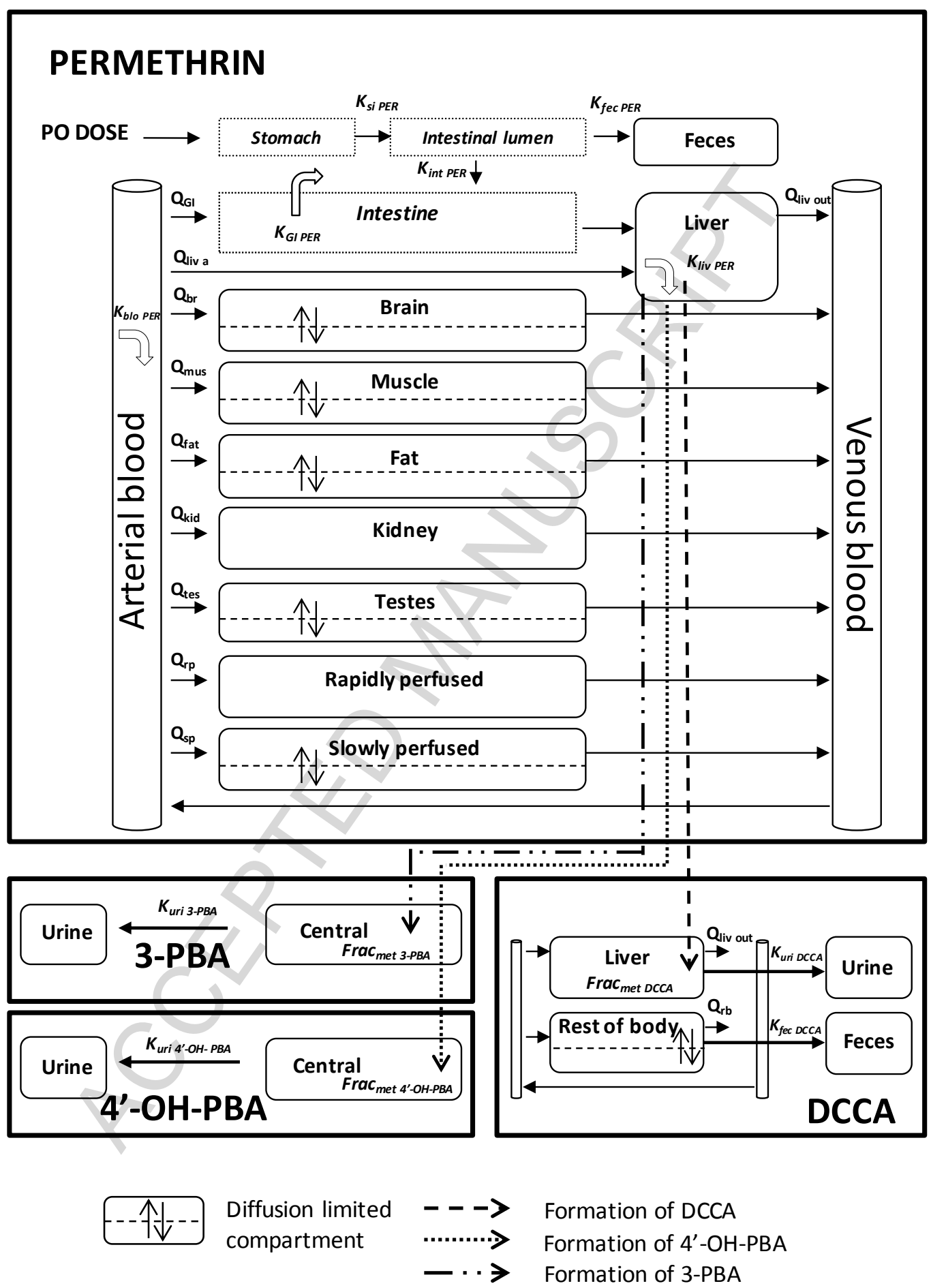

Figure 1. PBPK model of cis- and trans-permethrin (PER) and their metabolites cis- and transDCCA, 3-PBA and 4'-OH-PBA with an oral exposure. Distribution in brain, muscle, fat, testes and slowly perfused tissues of parent compounds and in rest of body of DCCA are limited by the diffusion and distribution in other organs by the flow. 3-PBA, DCCA, 4'-OH-PBA are formed in liver. 

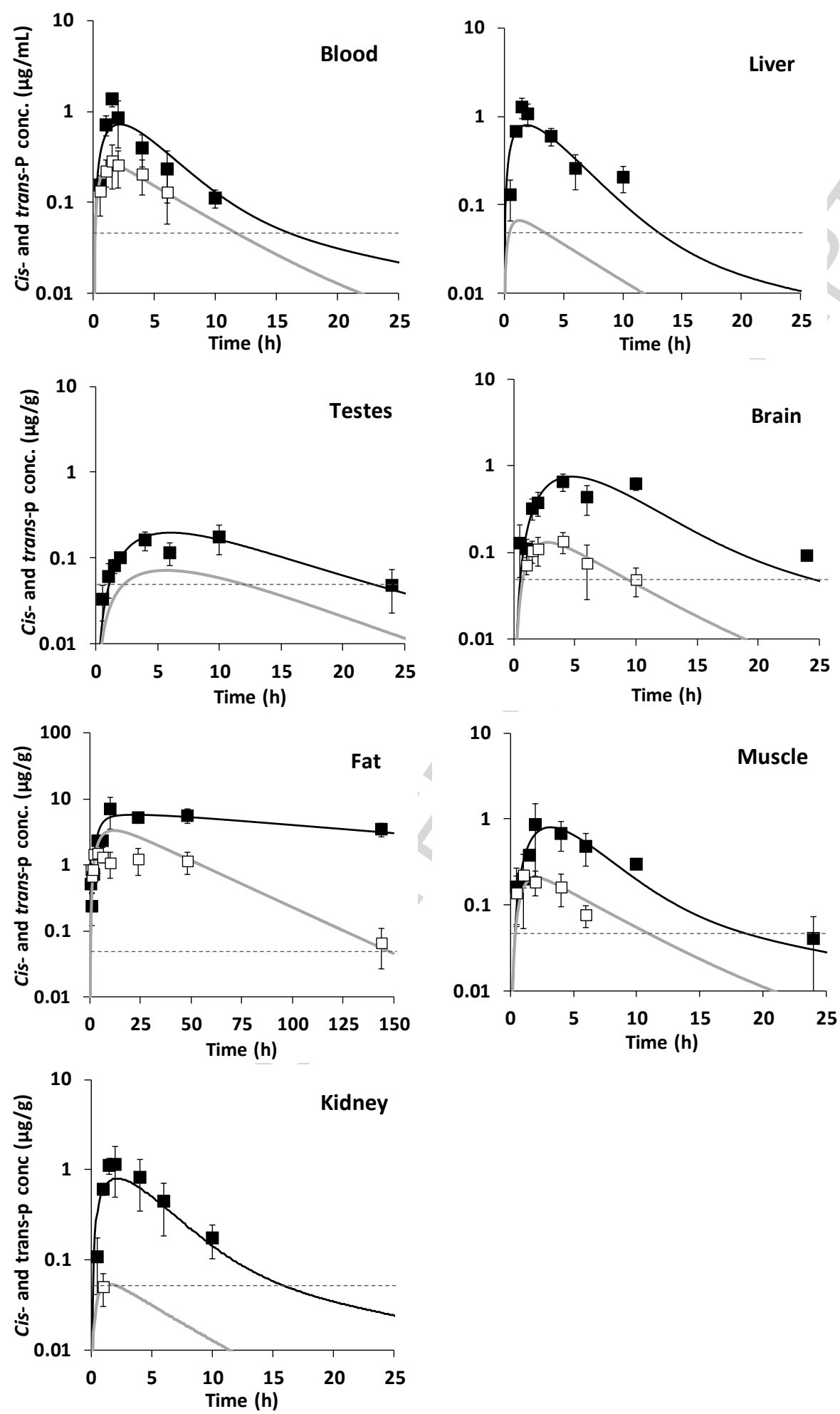

Figure 2. Measured concentrations (symbols) of cis-permethrin (cis-p) (-) and trans-permethrin (trans-p) ( $\square$ ) and toxicokinetic profiles estimated with the PBPK model (solid lines) of cis-permethrin (一) and trans-permethrin (-) in blood, liver, kidney, brain, testes, muscle and fat in rats after an exposure to $25 \mathrm{mg} / \mathrm{kg}$ of cis or trans-permethrin. The grey dotted line (- - -) stands for the LOQ of permethrin. 

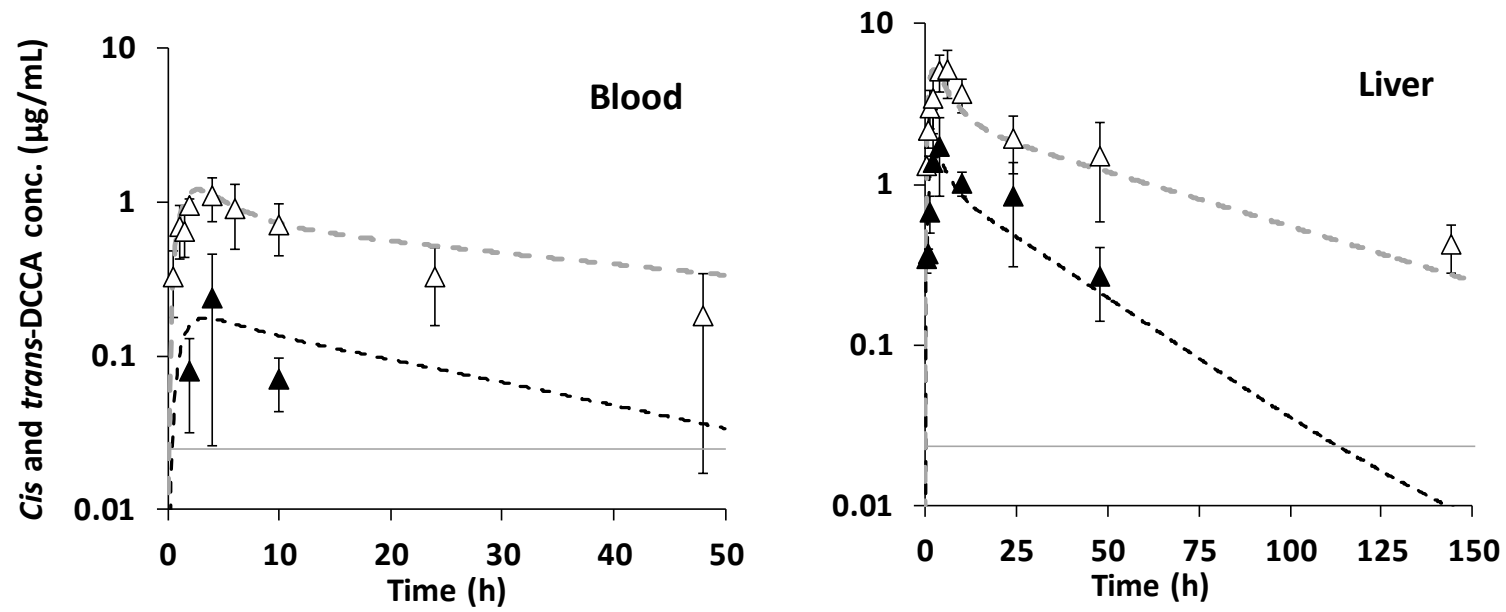

Figure 3. Measured concentrations of cis-DCCA $(\mathbf{\Delta})$ and trans-DCCA $(\Delta)$ and toxicokinetic profiles estimated with the PBPK model of cis-DCCA ( - - ) and trans-DCCA (- - in blood and liver in rats after an exposure to $25 \mathrm{mg} / \mathrm{kg}$ of cis or trans-permethrin. The grey solid line (一) stands for the LOQ of DCCA. 

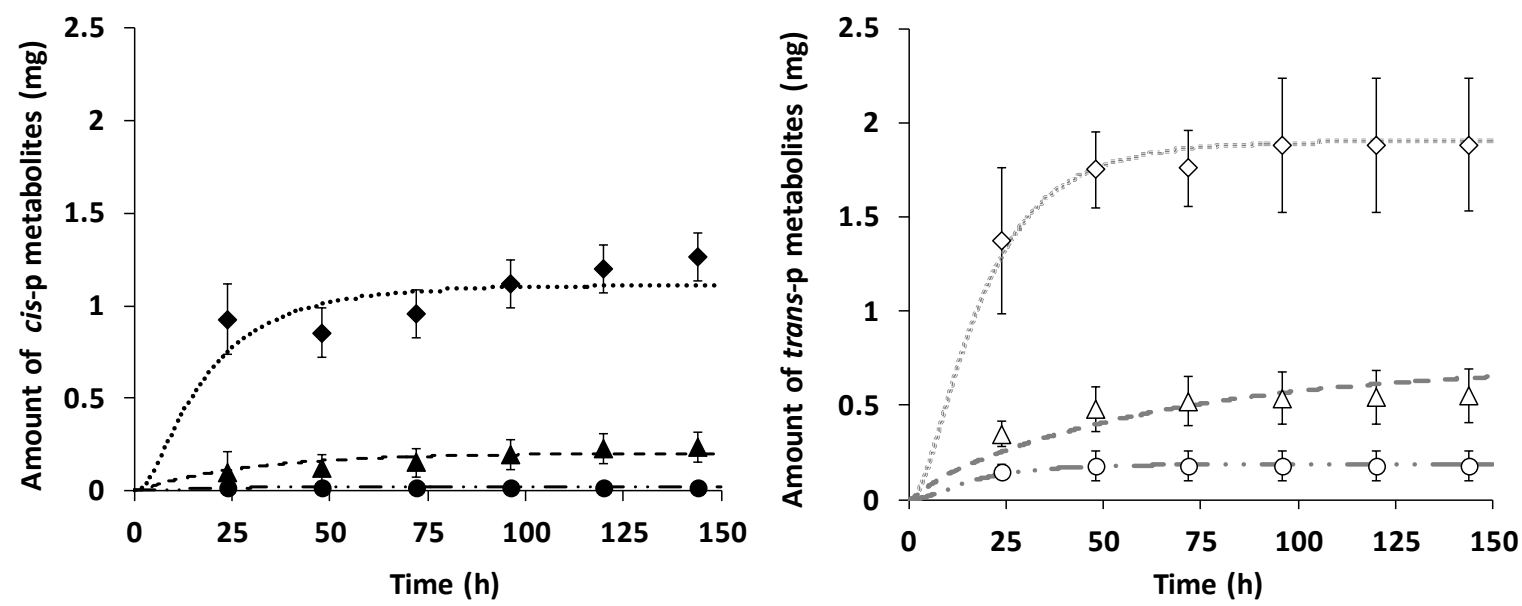

Figure 4. Kinetics of observed amounts in the metabolites 4'-OH-PBA $(\diamond)$, DCCA $(\Delta)$ and 3-PBA $(0)$ and estimated amounts in 4'-OH-PBA (..), DCCA ( - - and 3-PBA ( $~ . .-)$ in urine in rats after an exposure to $25 \mathrm{mg} / \mathrm{kg}$ of cis or trans-permethrin. Closed symbols and black lines are related to cispermethrin (cis-p) and open symbols and grey lines to trans-permethrin (trans-p). 

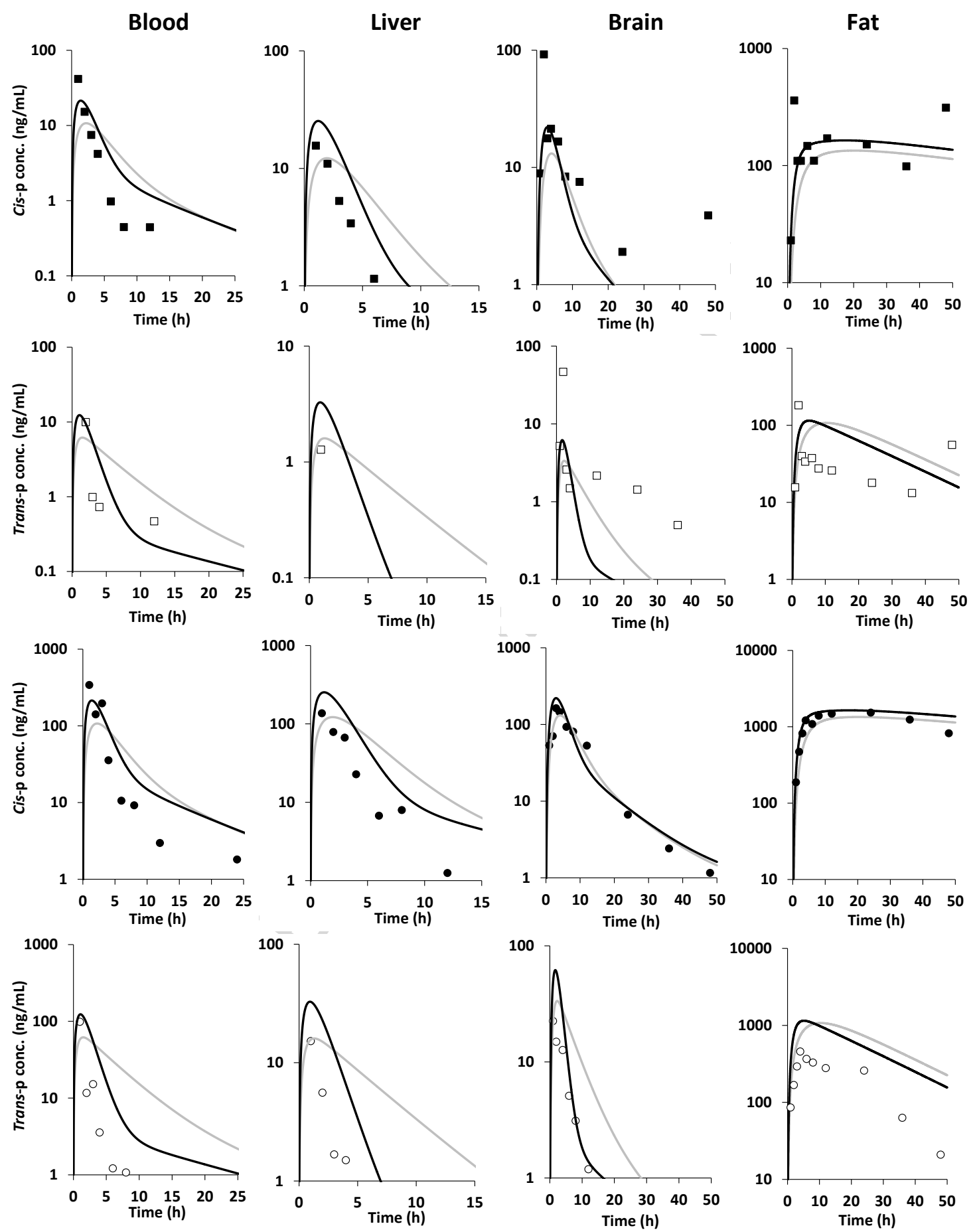

Figure 5. Observed concentrations in blood, liver, brain and fat after an oral dose of cis-permethrin at $0.4 \mathrm{mg} / \mathrm{kg}(\bullet)$ and $4 \mathrm{mg} / \mathrm{kg}(\bullet)$ and of trans-permethrin at $0.6 \mathrm{mg} / \mathrm{kg}(\square)$ and $6 \mathrm{mg} / \mathrm{kg}(\circ)$. The observed data are issued from the study of Tornero-Velez et al. (2012). The predicted concentrations from the values of parameters estimated with the extended PBPK model of permethrin and metabolites ( - ) and with the extended PBPK model with absorption rate fixed ( - ) are also represented. 


\section{List of Tables}

Table 1. Physiological parameters for PBPK models of cis- and trans-permethrin and metabolites cisand trans-DCCA, 3-PBA and 4'-OH-PBA in rats.

Table 2. Distributions of the cis- and trans-permethrin specific parameters of the PBPK model in rats. All prior distributions of parameters are truncated normal distributions represented by the average value \pm SD and their boundaries. Posterior distributions are represented by the mean with the $2.5^{\text {th }}$ and $97.5^{\text {th }}$ percentiles.

Table 3. Distributions of the specific parameters of DCCA, 3-PBA and 4'-OH-PBA of the PBPK model in rats. The prior distributions of all parameters are truncated normal distributions represented by the average value $\pm \mathrm{SD}$ and their boundaries, except the rate of formation of metabolites represented by a uniform distribution. Posterior distributions are represented by the mean with the $2.5^{\text {th }}$ and $97.5^{\text {th }}$ percentiles.

Table 4. Half-lives ( $T_{1 / 2}$, unit: h) of cis- and trans-permethrin and metabolites cis- and trans-DCCA in blood, brain, fat, kidney, liver, muscle and testes determined on observed concentrations. $\alpha$ and $\beta$ are respectively assigned to the first and the second slope of the curve.

Table 5. Average and standard deviation of values of the pharmacokinetic parameters the area under the curve of the observed concentrations $\left(\mathrm{AUC}_{\mathrm{obs}}\right)$ and the estimated concentrations $\left(\mathrm{AUC}_{\mathrm{est}}\right)$ ( $\mu \mathrm{g} . \mathrm{h} / \mathrm{mL})$ of cis- and trans-permethrin and cis- and trans-DCCA vs times in blood, brain, fat, kidney, liver, muscle and testes. 
Table 1. Physiological parameters for PBPK models of cis- and trans-permethrin and metabolites cisand trans-DCCA, 3-PBA and 4'-OH-PBA in rats.

\begin{tabular}{|c|c|c|}
\hline Parameters & Value & Source \\
\hline Body Weight (BW) (kg) & 0.47 & Exp data \\
\hline Total cardiac flow $\left(\mathrm{Q}_{\mathrm{c}}, \mathrm{L} / \mathrm{h} / \mathrm{kg}^{0.75}\right)$ & 14.1 & Brown et al. (1997) \\
\hline \multicolumn{3}{|l|}{ Relative tissue volumes ( $\%$ of $\mathrm{BW}$ ) } \\
\hline Blood $\left(\mathrm{V}_{\text {blo }}\right)$ & 7.4 & Brown et al. (1997) \\
\hline Brain $\left(\mathrm{V}_{\mathrm{bra}}\right)$ & 0.4 & Exp data \\
\hline Fat $\left(\mathrm{V}_{\text {fat }}\right)$ & 7.0 & Brown et al. (1997) \\
\hline Kidney $\left(\mathrm{V}_{\mathrm{kid}}\right)$ & 0.6 & Exp data \\
\hline GI tract $\left(\mathrm{V}_{\mathrm{gi}}\right)$ & 2.7 & Brown et al. (1997) \\
\hline Liver $\left(\mathrm{V}_{\text {liv }}\right)$ & 3.5 & Exp data \\
\hline Muscle $\left(\mathrm{V}_{\mathrm{mus}}\right)$ & 40.4 & Brown et al. (1997) \\
\hline Testes $\left(\mathrm{V}_{\text {tes }}\right)$ & 0.8 & Exp data \\
\hline Non perfused & 5 & Brown et al. (1997) \\
\hline Rapidly perfused $\left(\mathrm{V}_{\mathrm{rp}}\right)$ & 4.6 & Brown et al. (1997) \\
\hline Slowly perfused $\left(\mathrm{V}_{\mathrm{sp}}\right)$ & 27.6 & 1 - all organs - non perfused \\
\hline Rest of body ${ }^{\mathrm{a}}\left(\mathrm{V}_{\mathrm{rb}}\right)$ & 89.1 & 1 - blood - liver - non perfused \\
\hline \multicolumn{3}{|l|}{ Tissue blood flow ( $\%$ cardiac output) } \\
\hline Brain $\left(Q_{\text {bra }}\right)$ & 2.0 & Brown et al. (1997) \\
\hline Fat $\left(\mathrm{Q}_{\mathrm{fat}}\right)$ & 7.0 & Brown et al. (1997) \\
\hline Kidney $\left(Q_{\text {kid }}\right)$ & 14.1 & Brown et al. (1997) \\
\hline Liver (total) $\left(\mathrm{Q}_{\text {liv out }}\right)$ & 17.5 & Brown et al. (1997) \\
\hline Portal (GI tract) $(\mathrm{Q}$ & 15.1 & \\
\hline Arterial $\left(\mathrm{Q}_{\text {liv a }}\right)$ & 2.4 & \\
\hline Muscle $\left(Q_{\text {mus }}\right)$ & 27.8 & Brown et al. (1997) \\
\hline Testes $\left(\mathrm{Q}_{\mathrm{tes}}\right)$ & 0.4 & Waites (1991) \\
\hline Rapidly perfused $\left(\mathrm{Q}_{\mathrm{rp}}\right)$ & 24.9 & 1 - all organ flows \\
\hline Slowly perfused $\left(\mathrm{Q}_{\mathrm{sp}}\right)$ & 6.3 & Brown et al. (1997) \\
\hline Rest of body ${ }^{\mathrm{a}}\left(\mathrm{Q}_{\mathrm{rb}}\right)$ & 82.6 & 1 - total liver flow \\
\hline \multicolumn{3}{|l|}{ Blood volume fraction ( $\%$ of tissue) } \\
\hline Brain $\left(\mathrm{BV}_{\mathrm{bra}}\right)$ & 3 & Brown et al. (1997) \\
\hline Fat $\left(\mathrm{BV}_{\mathrm{fat}}\right)$ & 2 & Tornero-Velez et al. (2012) \\
\hline Slowly perfused $\left(\mathrm{BV}_{\mathrm{sp}}\right)$ & 4 & $\begin{array}{l}\text { Assimilated to muscle } \\
\text { Tornero-Velez et al. (2012) }\end{array}$ \\
\hline Testes $\left(\mathrm{BV}_{\mathrm{tes}}\right)$ & 4 & $\begin{array}{l}\text { Assimilated to muscle } \\
\text { Tornero-Velez } \text { et al. }(2012)\end{array}$ \\
\hline Rest of body ${ }^{a}\left(\mathrm{BV}_{\mathrm{rb}}\right)$ & 5 & \\
\hline
\end{tabular}

${ }^{a}$ : only for the PBPK model of the metabolite DCCA.

Note: GI tract tissue volume contains stomach, small and large intestines. Volume of the rapidly perfused tissues stands for heart, lung, adrenal, trabecular bone, marrow, pancreas, spleen and thyroid. Volume of the non perfused tissues stands for the GI tract content. Flow of slowly perfused tissues stands for cortical bones and skin. Rest of body corresponds to all the organs except liver. 
Table 2. Distributions of the cis- and trans-permethrin specific parameters of the PBPK model in rats.

All prior distributions of parameters are truncated normal distributions represented by the average value $\pm \mathrm{SD}$ and their boundaries. Posterior distributions are represented by the mean with the $2.5^{\text {th }}$ and $97.5^{\text {th }}$ percentiles.

\begin{tabular}{|c|c|c|c|c|}
\hline \multirow{2}{*}{ Parameters } & \multicolumn{2}{|c|}{ Prior distribution } & \multicolumn{2}{|c|}{ Posterior distribution } \\
\hline & Cis-Permethrin & Trans-Permethrin & Cis-Permethrin & Trans-Permethrin \\
\hline \multicolumn{5}{|l|}{ Partition coefficients } \\
\hline Brain:blood $\left(P C_{b r a}\right)$ & $\begin{array}{l}0.4 \pm 0.2 \\
{\left[10^{-3}-30\right]}\end{array}$ & $\begin{array}{l}0.4 \pm 0.2 \\
{\left[10^{-3}-30\right]}\end{array}$ & $\begin{array}{c}\mathbf{1 . 6} \\
{[1.4-1.8]}\end{array}$ & $\begin{array}{c}\mathbf{0 . 5 7} \\
{[0.49-0.66]}\end{array}$ \\
\hline Fat:blood $\left(P C_{f a t}\right)$ & $\begin{array}{l}150 \pm 75 \\
{[5-500]}\end{array}$ & $\begin{array}{l}50 \pm 25 \\
{[5-500]}\end{array}$ & $\begin{array}{c}\mathbf{2 2 5} \\
{[171-301]}\end{array}$ & $\begin{array}{c}76 \\
{[69-85]}\end{array}$ \\
\hline GI:blood $\left(P C_{g i}\right)$ & Equal to $P C_{k i d}$ & Equal to $P C_{k i c}$ & - & - \\
\hline Kidney:blood $\left(P C_{k i d}\right)$ & $\begin{array}{l}0.4 \pm 0.2 \\
{\left[10^{-3}-30\right]}\end{array}$ & $\begin{array}{l}0.4 \pm 0.2 \\
{\left[10^{-3}-30\right]}\end{array}$ & $\begin{array}{c}\mathbf{1 . 1} \\
{[1.0-1.2]}\end{array}$ & $\begin{array}{c}\mathbf{0 . 2 1} \\
{[0.16-0.27]}\end{array}$ \\
\hline Liver:blood $\left(P C_{l i v}\right)$ & $\begin{array}{l}0.4 \pm 0.2 \\
{\left[10^{-3}-30\right]}\end{array}$ & Equal to $P C_{k i d}$ & $\begin{array}{c}\mathbf{0 . 8 9} \\
{[0.80-0.99]}\end{array}$ & - \\
\hline Muscle:blood $\left(P C_{m u s}\right)$ & $\begin{array}{c}6 \pm 3 \\
{\left[10^{-3}-30\right]}\end{array}$ & $\begin{array}{c}6 \pm 3 \\
{\left[10^{-3}-30\right]}\end{array}$ & $\begin{array}{c}\mathbf{1 . 2} \\
{[1.0-1.5]}\end{array}$ & $\begin{array}{c}\mathbf{0 . 8 2} \\
{[0.70-0.95]}\end{array}$ \\
\hline Testes:blood $\left(P C_{t e s}\right)$ & $\begin{array}{l}0.4 \pm 0.2 \\
{\left[10^{-3}-30\right]}\end{array}$ & Equal to $P C_{b r a}$ & $\begin{array}{c}\mathbf{0 . 6 3} \\
{[0.54-0.72]}\end{array}$ & - \\
\hline Rapidly perfused:blood $\left(P C_{r p}\right)$ & Equal to $P C_{k i}$ & Equal to $P C_{k i d}$ & - & - \\
\hline Slowly perfused:blood $\left(P C_{s p}\right)$ & $\begin{array}{r}6 \pm 3 \\
{\left[10^{-3}-3\right.}\end{array}$ & $\begin{array}{c}6 \pm 3 \\
{\left[10^{-3}-30\right]}\end{array}$ & $\begin{array}{c}19 \\
{[15-23]}\end{array}$ & $\begin{array}{c}\mathbf{8 . 4} \\
{[2.4-14.2]}\end{array}$ \\
\hline \multicolumn{5}{|l|}{ Permeability coefficients $(\mathrm{L} / \mathrm{h})$} \\
\hline $\operatorname{Brain}\left(P A_{b r a}\right)$ & $\begin{array}{c}10^{-3} \pm 10^{-3} \\
{\left[10^{-5}-1\right]}\end{array}$ & $\begin{array}{c}10^{-3} \pm 10^{-3} \\
{\left[10^{-5}-1\right]}\end{array}$ & $\begin{array}{c}\mathbf{1 . 0 . 1 0}^{-3} \\
{\left[8 \cdot 4 \cdot 10^{-4}-1 \cdot 3 \cdot 10^{-3}\right]}\end{array}$ & $\begin{array}{c}\mathbf{1 . 2 . 1 0}^{-3} \\
{\left[0.8 \cdot 10^{-3}-1.6 .10^{-3}\right]}\end{array}$ \\
\hline Fat $\left(P A_{f a t}\right)$ & $\begin{array}{c}0.1 \pm 0.1 \\
{\left[10^{-5}-1\right]}\end{array}$ & $\begin{array}{c}0.1 \pm 0.1 \\
{\left[10^{-5}-1\right]}\end{array}$ & $\begin{array}{c}\mathbf{4 . 8 . 1 0}^{-2} \\
{\left[4.3 \cdot 10^{-2}-5 \cdot 4 \cdot 10^{-2}\right]}\end{array}$ & $\begin{array}{c}\mathbf{0 . 1 1} \\
{[0.09-0.12]}\end{array}$ \\
\hline Muscles $\left(P A_{m u s}\right)$ & $\begin{array}{c}0.1 \pm 0.1 \\
{\left[10^{-5}-1\right]}\end{array}$ & $\begin{array}{c}0.1 \pm 0.1 \\
{\left[10^{-5}-1\right]}\end{array}$ & $\begin{array}{c}\mathbf{0 . 3 2} \\
{[0.21-0.47]}\end{array}$ & $\begin{array}{c}\mathbf{0 . 4 8} \\
{[0.38-0.60]}\end{array}$ \\
\hline Testes $\left(P A_{t e s}\right)$ & $\begin{array}{l}10^{-3} \pm 10^{-3} \\
{\left[10^{-5}-1\right]}\end{array}$ & Equal to $P A_{b r a} / 3$ & $\begin{array}{c}\mathbf{3 . 3 . 1 0}^{-4} \\
{\left[2.7 \cdot 10^{-4}-4 \cdot 0 \cdot 10^{-4}\right]}\end{array}$ & - \\
\hline Slowly perfused $\left(P A_{s p}\right)$ & $\begin{array}{c}0.1 \pm 0.1 \\
{\left[10^{-5}-1\right]}\end{array}$ & $\begin{array}{c}0.1 \pm 0.1 \\
{\left[10^{-5}-1\right]}\end{array}$ & $\begin{array}{c}\mathbf{0 . 3 1} \\
{[0.22-0.41]}\end{array}$ & $\begin{array}{c}\mathbf{0 . 0 6 5} \\
{\left[9.10^{-3}-0.19\right]}\end{array}$ \\
\hline \multicolumn{5}{|l|}{ Rate constants $\left(\mathrm{h}^{-1}\right)$} \\
\hline Stomach-intestine transfer $\left(K_{s i}\right)$ & $\begin{array}{l}0.5 \pm 0.25 \\
{[0-2]}\end{array}$ & $\begin{array}{l}0.5 \pm 0.25 \\
{[0-2]}\end{array}$ & $\begin{array}{c}\mathbf{0 . 3 5} \\
{[0.30-0.40]}\end{array}$ & $\begin{array}{c}\mathbf{0 . 2 0} \\
{[0.17-0.23]}\end{array}$ \\
\hline Intestinal absorption $\left(K_{\text {int }}\right)$ & $\begin{array}{l}0.5 \pm 0.25 \\
\quad[0-2]\end{array}$ & $\begin{array}{c}0.5 \pm 0.25 \\
{[0-2]}\end{array}$ & $\begin{array}{c}\mathbf{0 . 5 2} \\
{[0.43-0.63]}\end{array}$ & $\begin{array}{c}\mathbf{1 . 3 0} \\
{[1.1-1.6]}\end{array}$ \\
\hline Fecal excretion $\left(K_{f e c}\right)$ & $\begin{array}{c}0.5 \pm 0.25 \\
{[0-2]}\end{array}$ & $\begin{array}{c}0.5 \pm 0.25 \\
{[0-2]}\end{array}$ & $\begin{array}{c}\mathbf{0 . 3 9} \\
{[0.31-0.47]}\end{array}$ & $\begin{array}{c}\mathbf{0 . 8 5} \\
{[0.68-1.06]}\end{array}$ \\
\hline \multicolumn{5}{|l|}{ Metabolic clearances } \\
\hline GI metabolism $(\mathrm{L} / \mathrm{h} / \mathrm{kg})\left(K_{g i}\right)$ & Fixed to 0.04 & Fixed to 0.3 & - & - \\
\hline Blood metabolism $(\mathrm{L} / \mathrm{h} / \mathrm{kg})\left(K_{b l o}\right)$ & Fixed to 0.07 & Fixed to 0.29 & - & - \\
\hline Liver metabolism $(\mathrm{L} / \mathrm{h} / \mathrm{kg})\left(K_{l i v}\right)$ & $\begin{array}{c}3 \pm 3 \\
{\left[10^{-5}-20\right]}\end{array}$ & $\begin{array}{c}10 \pm 10 \\
{\left[10^{-5}-40\right]}\end{array}$ & $\begin{array}{c}\mathbf{2 . 4} \\
{[2.2-2.7]}\end{array}$ & $\begin{array}{c}\mathbf{5 . 7} \\
{[5.0-6.4]}\end{array}$ \\
\hline
\end{tabular}


Table 3. Distributions of the specific parameters of DCCA, 3-PBA and 4'-OH-PBA of the PBPK model in rats. The prior distributions of all parameters are truncated normal distributions represented by the average value $\pm \mathrm{SD}$ and their boundaries, except the rate of formation of metabolites represented by a uniform distribution. Posterior distributions are represented by the mean with the $2.5^{\text {th }}$ and $97.5^{\text {th }}$ percentiles.

\begin{tabular}{|c|c|c|c|c|c|c|}
\hline \multirow{2}{*}{ Parameters } & \multicolumn{3}{|c|}{ Prior distribution } & \multicolumn{3}{|c|}{ Posterior distribution } \\
\hline & DCCA & 3-PBA & 4'-OH-PBA & DCCA & 3-PBA & 4'-OH-PBA \\
\hline \multicolumn{7}{|l|}{ Trans-permethrin } \\
\hline \multicolumn{7}{|l|}{ Partition coefficients } \\
\hline Liver:blood $\left(P C_{l i v}\right)$ & $\begin{array}{l}10 \pm 5 \\
{[1-30]}\end{array}$ & - & & $\begin{array}{c}\mathbf{4 . 4} \\
{[3.9-5.0]}\end{array}$ & - & - \\
\hline Rest of body:blood $\left(P C_{r b}\right)$ & $\begin{array}{l}10 \pm 5 \\
{[1-30]}\end{array}$ & - & & $\begin{array}{c}\mathbf{2 . 7} \\
{[2.2-3.3]}\end{array}$ & - & - \\
\hline \multicolumn{7}{|c|}{ Permeability coefficients $(\mathrm{L} / \mathrm{h})$} \\
\hline Rest of body:blood $\left(P A_{r b}\right)$ & $\begin{array}{c}0.1 \pm 0.1 \\
{\left[10^{-5}-2\right]}\end{array}$ & - & & $\begin{array}{c}\mathbf{0 . 2 5} \\
{[0.18-0.34]}\end{array}$ & - & - \\
\hline \multicolumn{7}{|c|}{ Fraction of metabolite formed } \\
\hline Fraction $\left(F_{r a c} c_{m e t}\right)$ & {$\left[10^{-5}-1\right]$} & {$\left[10^{-5}\right.$} & {$\left[10^{-5}-1\right]$} & $\begin{array}{c}\mathbf{0 . 5 2} \\
{[0.46-0.58]}\end{array}$ & $\begin{array}{c}\mathbf{0 . 0 4 8} \\
{[0.042-0.056]}\end{array}$ & $\begin{array}{c}\mathbf{0 . 4 5} \\
{[0.39-0.53]}\end{array}$ \\
\hline \multicolumn{7}{|l|}{ Rate constants } \\
\hline Fecal excretion $\left(\mathrm{h}^{-1}\right)\left(K_{f e c}\right)$ & $\begin{array}{l}0.5 \pm 0.25 \\
{[0-2]}\end{array}$ & & - & $\begin{array}{c}\mathbf{0 . 4 2} \\
{[0.36-0.48]}\end{array}$ & - & - \\
\hline Urine excretion ${ }^{\mathrm{a}}\left(K_{u r i}\right)$ & $\begin{array}{c}0.05 \pm 0.025 \\
{[0-0.2]}\end{array}$ & $\begin{array}{c}0.05 \pm 0.025 \\
{[0-0.2]}\end{array}$ & $\begin{array}{c}0.05 \pm 0.025 \\
{[0-0.2]}\end{array}$ & $\begin{array}{c}\mathbf{0 . 0 1 7} \\
{[0.015-0.020]}\end{array}$ & $\begin{array}{c}\mathbf{0 . 0 7 8} \\
{[0.051-0.114]}\end{array}$ & $\begin{array}{c}\mathbf{0 . 0 7 1} \\
{[0.045-0.104]}\end{array}$ \\
\hline \multicolumn{7}{|l|}{ Cis-permethrin } \\
\hline \multicolumn{7}{|l|}{ Partition coefficients } \\
\hline Liver:blood $\left(P C_{l i v}\right)$ & $\begin{array}{l}10 \pm 5 \\
{[1-30]}\end{array}$ & - & - & $\begin{array}{c}\mathbf{6 . 3} \\
{[5.3-7.6]}\end{array}$ & - & - \\
\hline Rest of body:blood $\left(P C_{r b}\right)$ & $\begin{array}{l}10 \pm 5 \\
{[1-30]}\end{array}$ & - & - & $\begin{array}{c}\mathbf{3 . 4} \\
{[2.7-4.1]}\end{array}$ & - & - \\
\hline Permeability coefficients & & & & & & \\
\hline Rest of body:blood $\left(P A_{r b}\right)$ & $\begin{array}{c}0.1 \pm 0.1 \\
{\left[10^{-5}-2\right]}\end{array}$ & - & - & $\begin{array}{c}\mathbf{0 . 8 5} \\
{[0.72-0.98]}\end{array}$ & - & - \\
\hline \multicolumn{7}{|c|}{ Fraction of metabolite formed } \\
\hline Fraction $\left(\right.$ Frac $\left._{m e t}\right)$ & {$\left[10^{-5}-1\right]$} & {$\left[10^{-5}-1\right]$} & {$\left[10^{-5}-1\right]$} & $\begin{array}{c}\mathbf{0 . 2 2} \\
{[0.19-0.25]}\end{array}$ & $\begin{array}{c}\mathbf{5 . 4 . 1 0} \mathbf{0}^{-3} \\
{\left[4.6 \cdot 10^{-3}-6.3 \cdot 10^{-3}\right]}\end{array}$ & $\begin{array}{c}\mathbf{0 . 2 9} \\
{[0.25-0.33]}\end{array}$ \\
\hline \multicolumn{7}{|l|}{ Rate constants } \\
\hline Fecal excretion $\left(\mathrm{h}^{-1}\right)\left(K_{f e c}\right)$ & $\begin{array}{l}0.5 \pm 0.25 \\
{[0-2]}\end{array}$ & - & - & $\begin{array}{c}\mathbf{1 . 0} \\
{[0.9-1.2]}\end{array}$ & - & - \\
\hline Urine excretion $^{\mathrm{a}}\left(K_{u r i}\right)$ & $\begin{array}{c}0.05 \pm 0.025 \\
{[0-0.2]}\end{array}$ & $\begin{array}{c}0.05 \pm 0.025 \\
{[0-0.2]}\end{array}$ & $\begin{array}{c}0.05 \pm 0.025 \\
{[0-0.2]}\end{array}$ & $\begin{array}{c}\mathbf{0 . 0 3 8} \\
{[0.031-0.047]}\end{array}$ & $\begin{array}{c}\mathbf{0 . 0 7 5} \\
{[0.048-0.111]}\end{array}$ & $\begin{array}{c}\mathbf{0 . 0 7 0} \\
{[0.044-0.103]}\end{array}$ \\
\hline
\end{tabular}

${ }^{\mathrm{a}}$ : the urine clearance of the DCCA is expressed in L/h and the rate of urine elimination of 3-PBA and 4'-OH-PBA in $\mathrm{h}^{-1}$. 
Table 4. Half-lives ( $T_{1 / 2}$, unit: h) of cis- and trans-permethrin and metabolites cis- and trans-DCCA in blood, brain, fat, kidney, liver, muscle and testes determined on observed concentrations. $\alpha$ and $\beta$ are respectively assigned to the first and the second slope of the curve.

\begin{tabular}{|c|c|c|c|c|c|c|c|c|}
\hline & \multicolumn{3}{|c|}{ Cis-Permethrin } & Trans-Permethrin & \multicolumn{2}{|c|}{ Cis-DCCA } & \multicolumn{2}{|c|}{ Trans-DCCA } \\
\hline & $T_{1 / 2}$ & $T_{1 / 2} \alpha$ & $T_{1 / 2} \beta$ & $T_{1 / 2}$ & $T_{1 / 2} \alpha$ & $T_{1 / 2} \beta$ & $T_{1 / 2} \alpha$ & $T_{1 / 2} \beta$ \\
\hline Blood & - & 1.5 & 3.3 & 4.2 & 3.4 & & 12.0 & 30.1 \\
\hline Brain & 7.2 & - & - & 4.3 & & & - & - \\
\hline Fat & 139 & - & - & 23.1 & & - & - & - \\
\hline Kidney & 2.9 & - & - & $-{ }^{a}$ & & - & - & - \\
\hline Liver & - & 2.0 & 11.7 & $-{ }^{a}$ & & - & 13.6 & 53.3 \\
\hline Muscle & 5.0 & - & - & 3.5 & & - & - & - \\
\hline Testes & 12.0 & - & - & $-{ }^{a}$ & & - & - & - \\
\hline
\end{tabular}


Table 5. Average and standard deviation of values of the pharmacokinetic parameters the area under the curve of the observed concentrations $\left(\mathrm{AUC}_{\mathrm{obs}}\right)$ and the estimated concentrations $\left(\mathrm{AUC}_{\mathrm{est}}\right)$ ( $\mu \mathrm{g} . \mathrm{h} / \mathrm{mL})$ of cis- and trans-permethrin and cis- and trans-DCCA vs times in blood, brain, fat, kidney, liver, muscle and testes.

\begin{tabular}{|c|c|c|c|c|c|c|c|c|}
\hline & \multicolumn{2}{|c|}{ Cis-permethrin } & \multicolumn{2}{|c|}{ Trans-permethrin } & \multicolumn{2}{|c|}{ Cis-DCCA } & \multicolumn{2}{|c|}{ Trans-DCCA } \\
\hline & $\mathbf{A U C}_{\text {obs }}$ & $\mathbf{A U C}_{\text {est }}$ & $\mathbf{A U C}_{\text {obs }}$ & $\mathbf{A U C}_{\text {est }}$ & $\mathbf{A U C}_{\text {obs }}$ & $\mathbf{A U C}_{\text {est }}$ & $\mathbf{A U C}_{\text {obs }}$ & $\mathbf{A U C}_{\text {est }}$ \\
\hline Blood & 4.5 & $5.5 \pm 0.1$ & $1.8^{\mathrm{a}}$ & $2.0 \pm 0.1$ & 7 & $.4 \pm 0.6$ & 37.5 & $41.4 \pm 2.7$ \\
\hline Brain & 10.2 & $8.7 \pm 0.5$ & $1.1^{\mathrm{a}}$ & $1.2 \pm 0.08$ & & - & - & - \\
\hline Fat & $1366^{\mathrm{a}}$ & $1180 \pm 162$ & 117 & $148 \pm 7$ & & - & - & - \\
\hline Kidney & 6.4 & $6.0 \pm 0.3$ & - & $0.41 \pm 0.06$ & & - & - & - \\
\hline Liver & $5.9^{\mathrm{a}}$ & $5.0 \pm 0.2$ & - & $0.45 \pm 0.06$ & & $34.8 \pm 2.1$ & 245.8 & $184 \pm 10$ \\
\hline Muscle & 7.5 & $6.6 \pm 0.5$ & $1.4^{\mathrm{a}}$ & $1.6 \pm 0$. & & - & - & - \\
\hline Testes & 3.3 & $3.5 \pm 0.2$ & - & $1.2 \pm 0.8$ & - & - & - & - \\
\hline
\end{tabular}

${ }^{a}$ : value of extrapolated AUC was over $20 \%$ but not exceeded $50 \%$ of the total AUC.

Note: $\mathrm{AUC}_{\mathrm{obs}}$ was defined as the sum of the AUC computed with the trapezoidal rule on observed concentrations and the $\mathrm{AUC}_{\text {est }}$, defined as the last observed concentration divided by the elimination rate. 


\section{Highlights}

- A PBPK model of isomers of permethrin and its urinary metabolites was developed

- A quantitative link was established for permethrin and its biomarkers of exposure

- The bayesian framework allows getting confidence interval on the estimated parameters

- The PBPK model can be extrapolated to human and used in a reverse dosimetry context 